FEDERAL RESERVE BANK OF SAN FRANCISCO

WORKING PAPER SERIES

\title{
Rational and Near-Rational Bubbles Without Drift
}

Kevin J. Lansing

Federal Reserve Bank of San Francisco

October 2009

Working Paper 2007-10

http://www.frbsf.org/publications/economics/papers/2007/wp07-10bk.pdf

The views in this paper are solely the responsibility of the authors and should not be interpreted as reflecting the views of the Federal Reserve Bank of San Francisco or the Board of Governors of the Federal Reserve System. 


\title{
Rational and Near-Rational Bubbles Without Drift*
}

\author{
Kevin J. Lansing ${ }^{\dagger}$ \\ Federal Reserve Bank of San Francisco
}

October 8, 2009

\begin{abstract}
This paper derives a general class of intrinsic rational bubble solutions in a Lucas-type asset pricing model. I show that the rational bubble component of the price-dividend ratio can evolve as a geometric random walk without drift, such that the mean of the bubble growth rate is zero. Driftless bubbles are part of a continuum of equilibrium solutions that satisfy a period-by-period no-arbitrage condition. I also derive a nearrational solution in which the agent's forecast rule is under-parameterized. The nearrational solution generates intermittent bubbles and other behavior that is quantitatively similar to that observed in long-run U.S. stock market data.
\end{abstract}

Keywords: Asset Pricing, Rational Bubbles, Excess Volatility, Learning.

JEL Classification: E44, G12.

\footnotetext{
${ }^{*}$ Forthcoming, Economic Journal. For helpful comments and suggestions, I would like to thank Eric Engstrom, Steve LeRoy, Kjersti-Gro Lindquist, participants at the 2007 Meeting of the Society for Economic Dynamics, the 2007 Meeting of the Society for Computational Economics, the 2007 Meeting of the Society for Nonlinear Dynamics and Econometrics, and the 2008 Norges Bank Symposium on Fundamental and Nonfundamental Asset Price Dynamics. I also thank two anonymous referees for thoughtful suggestions that improved the paper.

† Research Department, Federal Reserve Bank of San Francisco, P.O. Box 7702, San Francisco, CA 94120-7702, (415) 974-2393, FAX: (415) 977-4031, email: kevin.j.lansing@sf.frb.org, homepage: www.frbsf.org/economics/economists/klansing.html
} 
Nowhere does history indulge in repetitions so often or so uniformly as in Wall Street. When you read contemporary accounts of booms or panics the one thing that strikes you most forcibly is how little either stock speculation or stock speculators today differ from yesterday. The game does not change and neither does human nature.

From the thinly-disguised biography of legendary speculator Jesse Livermore, by E. Lefevére (1923, p. 180).

\section{Introduction}

Stories involving speculative bubbles can be found throughout history in various countries and asset markets. ${ }^{1}$ The dramatic rise in U.S. stock prices during the late 1990s, followed similarly by U.S. house prices during the mid 2000s, are episodes that have both been described as bubbles. The term "bubble" was coined in England in 1720 following the famous price run-up and crash of shares in the South Sea Company. The run-up led to widespread public enthusiasm for the stock market and a proliferation of highly suspect companies attempting to sell shares to investors. One such venture notoriously advertised itself as "a company for carrying out an undertaking of great advantage, but nobody to know what it is." The epidemic of fraudulent stock-offering schemes led the British government to pass the so-called "Bubble Act" in 1720, which was officially named "An Act to Restrain the Extravagant and Unwarrantable Practice of Raising Money by Voluntary Subscription for Carrying on Projects Dangerous to the Trade and Subjects of the United Kingdom." 2

Numerous empirical studies starting with Shiller (1981) and LeRoy and Porter (1981) have demonstrated that stock prices appear to exhibit "excess volatility" when compared to the discounted stream of ex post realized dividends. ${ }^{3}$ Bubble models offer a potential explanation for excess volatility because they allow stock prices to become detached from fundamentals. So-called "rational bubble" models say that agents are fully cognizant of the fundamental asset price, but nevertheless they may be willing to pay more than this amount. This can occur if expectations of future price appreciation are large enough to satisfy the rational agents's required rate of return. In the typical rational bubble model, the stock price grows faster than dividends (or cash flows) in perpetuity, i.e., the price-dividend ratio exhibits positive drift. This is clearly an unrealistic prediction for long-run stock market behavior. Indeed, Hall (2001, p. 3) dismisses the idea that "intelligent people [would] believe that the value of a stock will become larger and larger in relation to all other quantities in the economy." A more elaborate model assumes that the bubble will periodically crash according to some universally known probability function, but this is an ad hoc feature that is determined completely outside of the model. ${ }^{4}$ Notwithstanding these criticisms, LeRoy $(2004$, p.784) maintains that "[rational] bubbles are a viable candidate for an explanation for the volatility of asset prices, even if it is

\footnotetext{
${ }^{1}$ See, for example, the collection of papers in Hunter, Kaufman, and Pomerleano (2003).

${ }^{2}$ See Gerding (2006).

${ }^{3}$ Shiller (2003) provides an update on this literature.

${ }^{4}$ Rational bubble models with exogenous crash probablities include Blanchard (1979), Blanchard and Watson (1982), Evans (1991), Fukata (1998), and Van Norden and Schaller (1999), among others.
} 
not entirely clear how bubbles should be modeled."

This paper derives a rational bubble solution that is less susceptible to some of the above criticisms. The framework for the analysis is a standard Lucas (1978) type asset pricing model. For any given value of risk aversion, I show that there are two distinct rational bubble solutions for which the bubble component of the price-dividend ratio evolves as a geometric random walk without drift, such that the unconditional mean of the bubble growth rate is zero. Under each solution, the volatility of bubble innovations depends exclusively on fundamentals, i.e., the bubble is "intrinsic" in the terminology of Froot and Obstfeld (1991). Starting from an arbitrarily small positive value, a driftless rational bubble expands and contracts over time in a irregular, wholly endogenous fashion. Although the price-dividend ratio remains non-stationary, the equilibrium trajectory is less explosive than a bubble with positive drift. I show that driftless rational bubbles are part of a continuum of equilibrium solutions that satisfy a period-by-period no-arbitrage condition. The positive-drift bubble solution derived by Froot and Obstfeld (1991) can be recovered as a special case along this continuum.

Rational bubble models assume that agents always know the size of the bubble - to the point of constructing separate forecasts for the fundamental and bubble components of the asset price. An agent with limited computational resources may be inclined to construct only a single forecast that predicts the movement of the total asset price (fundamental plus bubble). As noted by Nerlove (1983, p. 1255): "Purposeful economic agents have incentives to eliminate errors up to a point justified by the costs of obtaining the information necessary to do so." Furthermore, rational bubble models are silent on how agents would coordinate on a particular rational bubble solution among a continuum of available solutions. To address such concerns, I solve for a near-rational equilibrium in which the agent's forecast rule for the total asset price is based on a geometric random walk without drift. The innovations to the random walk are linked to observable fundamentals, namely, consumption/dividend growth. The agent's forecast rule is similar in form to the corresponding rational forecast, but it involves fewer parameters. The parameters of the agent's forecast rule are chosen to match the moments of observable data. Using a real-time learning algorithm, I demonstrate that the near-rational solution is learnable.

The actual law of motion for the near-rational price-dividend ratio turns out to be stationary, highly persistent, and nonlinear. The agent's forecast errors exhibit near-zero autocorrelation at all lags, making it difficult for the agent to detect a misspecification of the subjective forecast rule. Unlike a rational bubble, the near-rational solution allows the asset price to occasionally dip below its fundamental value. Under mild risk aversion, the near-rational solution generates pronounced low-frequency swings in the price-dividend ratio, positive skewness, excess kurtosis, and time-varying volatility - all of which are present in long-run U.S. stock market data.

An additional contribution of the paper is to demonstrate an approximate analytical solution for the fundamental asset price that employs a nonlinear change of variables. The behavior of the changed variable is well-captured by a simple exponential function, as opposed to the high-order polynomial function employed in the approximate solution derived by Calin, et. al (2005). I show that the exponential approximation yields results that are very close to the 
exact theoretical solution derived by Burnside (1998) for the case of autocorrelated dividend growth.

The near-rational asset pricing solution developed here is related to a large body of research that seeks to explain stock market behavior using some type of distorted belief mechanism or misspecified forecast rule in a representative agent framework. Examples along these lines include Barsky and Delong (1993), Timmerman (1996), Barberis, Shleifer, and Vishney (1998), Cecchetti, Lam, and Mark (2000), Abel (2002), Lansing (2006, 2009), Branch and Evans (forthcoming), and Bullard, Evans, and Honkapohja (forthcoming), among others. Bubble models that involve the interaction of rational and non-rational agents in the same economy include Delong et al. (1990), Brock and Hommes (1998), Abreu and Brunnermeier (2003), and Scheinkman and Xiong (2003).

Another related paper in one by Adam, Marcet, and Nicolini (2008), who also develop a near-rational asset pricing solution. The authors introduce bounded-rationality in the form of learning to account for several quantitative features of U.S. stock market data, including the high volatility and persistence of the price-dividend ratio. In their model, the representative agent constructs separate forecasts for dividend growth and for price growth. The agent has rational expectations regarding dividend growth, but the agent employs a momentum-based forecast rule for price growth. Given sufficient data, the learning algorithm for price growth eventually converges to the fundamental solution. In contrast, I consider a solution where the agent constructs a forecast for a composite variable that depends on both prices and dividends. The functional form of the agent's forecast rule is motivated by the form of the driftless rational bubble solution. Since the agent's forecast rule does not nest the fundamental solution as a special case, the long-run equilibrium continues to exhibit excess volatility.

The paper is organized as follows. First, I describe the model and the approximate fundamental solution. I then demonstrate the existence of a continuum of nonstationary, intrinsic rational bubble solutions and highlight some special cases along the continuum. Next, I develop a stationary, near-rational asset pricing solution that involves a parsimonious forecast rule which is parameterized by matching the moments of observable data. Finally, using numerical simulations, I show that the near-rational solution performs well in matching features of long-run U.S. stock market data.

\section{The Model}

Equity shares are priced using the frictionless pure exchange model of Lucas (1978). There is a representative agent who can purchase shares to transfer wealth from one period to another. Each share pays an exogenous stream of stochastic dividends in perpetuity.

The agent's problem is to maximize

$$
E_{0} \sum_{t=0}^{\infty} \beta^{t}\left[\frac{c_{t}^{1-\alpha}-1}{1-\alpha}\right],
$$

subject to the budget constraint

$$
c_{t}+p_{t} s_{t}=\left(p_{t}+d_{t}\right) s_{t-1}, \quad c_{t}, s_{t} \geq 0
$$


where $c_{t}$ is the agent's consumption in period $t, \beta$ is the subjective time discount factor, and $\alpha$ is the coefficient of relative risk aversion (the inverse of the intertemporal elasticity of substitution). When $\alpha=1$, the within-period utility function can be written as $\log \left(c_{t}\right)$. The symbol $E_{t}$ represents the mathematical expectation operator evaluated using the objective distribution of dividend growth. The symbol $p_{t}$ denotes the ex-dividend price of the equity share, $d_{t}$ is the dividend, and $s_{t}$ is the number of shares held in period $t$.

The growth rate of dividends $x_{t} \equiv \log \left(d_{t} / d_{t-1}\right)$ is governed by the following stochastic process

$$
x_{t}=\bar{x}+\rho\left(x_{t-1}-\bar{x}\right)+\varepsilon_{t}, \quad \varepsilon_{t} \sim N\left(0, \sigma_{\varepsilon}^{2}\right),
$$

where $|\rho|<1$. The mean growth rate is $\bar{x}$ and the variance is $\sigma_{\varepsilon}^{2} /\left(1-\rho^{2}\right)$.

The first-order condition that governs the agent's share holdings is given by

$$
p_{t}=E_{t}\left[\beta\left(\frac{c_{t+1}}{c_{t}}\right)^{-\alpha}\left(p_{t+1}+d_{t+1}\right)\right] .
$$

Equation (4) can be rearranged to obtain

$$
1=E_{t}\left[M_{t+1} R_{t+1}\right]
$$

where $M_{t+1} \equiv \beta\left(c_{t+1} / c_{t}\right)^{-\alpha}$ is the stochastic discount factor and $R_{t+1}=\left(p_{t+1}+d_{t+1}\right) / p_{t}$ is the gross return from holding the equity share from period $t$ to $t+1$. Defining the price-dividend ratio as $y_{t} \equiv p_{t} / d_{t}$, the gross equity return can be written as

$$
R_{t+1}=\left(\frac{y_{t+1}+1}{y_{t}}\right) \exp \left(x_{t+1}\right) \text {. }
$$

Following Lucas (1978), equity shares are assumed to exist in unit net supply. Market clearing therefore implies $s_{t}=1$ for all $t$. Substituting this equilibrium condition into the budget constraint (2) yields, $c_{t}=d_{t}$ for all $t$. In equilibrium, equation (4) can now be written as

$$
y_{t}=E_{t}\left[\beta \exp \left(\theta x_{t+1}\right)\left(y_{t+1}+1\right)\right]
$$

where $\theta \equiv 1-\alpha$. Equation (7) shows that the price-dividend ratio in period $t$ depends on the agent's joint forecast of next period's dividend growth rate $x_{t+1}$ and next period's pricedividend ratio $y_{t+1}$. It is convenient to transform equation (7) using a nonlinear change of variables to obtain

$$
z_{t}=\beta \exp \left(\theta x_{t}\right)\left[E_{t} z_{t+1}+1\right],
$$

where $z_{t} \equiv \beta \exp \left(\theta x_{t}\right)\left(y_{t}+1\right)$. Under this formulation, $z_{t}$ represents a composite variable that depends on both the growth rate of dividends and the price-dividend ratio. Equation (8) shows that the value of $z_{t}$ in period $t$ depends on the agent's conditional forecast of that same variable. By making use of the definition of $z_{t}$, equation (7) can be written as $y_{t}=E_{t} z_{t+1}$. Hence, the equilibrium price-dividend ratio is simply the conditional forecast of the composite variable $z_{t+1} \cdot{ }^{5}$

\footnotetext{
${ }^{5}$ The appendix outlines a version of the model that allows $c_{t} \neq d_{t}$.
} 


\section{Fundamental Solution}

The fundamental value of the share price is uniquely pinned down by the agent's rational forecast of the discounted stream of future dividends. Equation (8) can be iterated forward to substitute out $z_{t+1+k}$ for $k=0,1,2, \ldots$ Applying the law of iterated expectations and imposing a transversality condition yields the following present-value pricing equation

$$
\begin{aligned}
z_{t}^{\mathrm{f}}= & \beta \exp \left(\theta x_{t}\right) E_{t}\left\{1+\beta \exp \left(\theta x_{t+1}\right)+\beta^{2} \exp \left(\theta x_{t+1}+\theta x_{t+2}\right)+\right. \\
& \left.\beta^{3} \exp \left(\theta x_{t+1}+\theta x_{t+2}+\theta x_{t+3}\right) \ldots\right\}
\end{aligned}
$$

where $z_{t}^{\mathrm{f}}$ is the fundamental value of the composite forecast variable. Following Burnside (1998), the expectation of the infinite sum in (9) can be explicitly evaluated to yield the following exact analytical solution

$$
\begin{aligned}
z_{t}^{\mathrm{f}} & =\beta \exp \left(\theta x_{t}\right)\left\{1+\sum_{i=1}^{\infty} \beta^{i} \exp \left[\kappa_{i}+\gamma_{i}\left(x_{t}-\bar{x}\right)\right]\right\} \\
\kappa_{i} & =\theta \bar{x} i+\frac{\theta^{2} \sigma_{\varepsilon}^{2}}{2\left(1-\rho^{2}\right)}\left[i-\frac{2 \rho\left(1-\rho^{i}\right)}{1-\rho}+\frac{\rho^{2}\left(1-\rho^{2 i}\right)}{1-\rho^{2}}\right], \\
\gamma_{i} & =\frac{\theta \rho\left(1-\rho^{i}\right)}{1-\rho} .
\end{aligned}
$$

Given $z_{t}^{\mathrm{f}}$, we can recover the fundamental price-dividend ratio by applying the definitional relationship $y_{t}^{\mathrm{f}}=\beta^{-1} \exp \left(-\theta x_{t}\right) z_{t}^{\mathrm{f}}-1$. This procedure yields the result that $y_{t}^{\mathrm{f}}$ is equal to the infinite sum inside the curly brackets in equation (10). In the special case when $\rho=0$, we have $\gamma_{i}=0$ such that $y_{t}^{\mathrm{f}}$ is constant. ${ }^{6}$

In model simulations, computation of the (truncated) infinite sum in equation (10) for each realization of $x_{t}$ is quite time consuming. Moreover, equation (10) does not lend itself to analytical moment calculations for the asset pricing variables of interest. To avoid these drawbacks, the following proposition presents an approximate analytical solution for $z_{t}^{\mathrm{f}}$.

Proposition 1. An approximate analytical solution for the fundamental value of the composite forecast variable is given by

$$
z_{t}^{\mathrm{f}}=\exp \left[a_{0}+a_{1}\left(x_{t}-\bar{x}\right)\right]
$$

where $a_{1}$ solves the following nonlinear equation

$$
a_{1}=\frac{\theta}{1-\rho \beta \exp \left[\theta \bar{x}+\frac{1}{2}\left(a_{1}\right)^{2} \sigma_{\varepsilon}^{2}\right]},
$$

\footnotetext{
${ }^{6}$ Throughout the paper, I use Greek letters such as $\kappa, \gamma$, and $\lambda$, to represent constants implied by exact analytical solutions and English letters such as $a, b, k$, and $m$ to represent constants implied by approximate analytical solutions.
} 
and $a_{0} \equiv E\left[\log \left(z_{t}^{\mathrm{f}}\right)\right]$ is given by

$$
a_{0}=\log \left\{\frac{\beta \exp (\theta \bar{x})}{1-\beta \exp \left[\theta \bar{x}+\frac{1}{2}\left(a_{1}\right)^{2} \sigma_{\varepsilon}^{2}\right]}\right\},
$$

provided that $1>\beta \exp \left[\theta \bar{x}+\frac{1}{2}\left(a_{1}\right)^{2} \sigma_{\varepsilon}^{2}\right]$.

Proof: See appendix.

Two values of $a_{1}$ satisfy the nonlinear equation. The inequality restriction selects the value of $a_{1}$ with lower magnitude to ensure that the point of approximation $\exp \left(a_{0}\right)$ is positive. The approximate solution in Proposition 1 is much simpler in structure than the one derived by Calin, et. al (2005) for their corresponding model with no habit formation. These authors numerically approximate the law of motion of the changed variable $q_{t}^{\mathrm{f}} \equiv \exp \left(-\rho \theta x_{t}\right) y_{t}^{\mathrm{f}}$ using a polynomial of the form

$$
\underbrace{\left(\frac{d_{t}}{d_{t-1}}\right)^{-\rho(1-\alpha)}\left(\frac{p_{t}^{\mathrm{f}}}{d_{t}}\right)}_{q_{t}^{\mathrm{f}}}=\widehat{a}_{0}+\sum_{i=1}^{8} \widehat{a}_{i}\left(x_{t}-\bar{x}\right)^{i},
$$

which involves a total of nine Taylor-series coefficients. ${ }^{7}$ In contrast, Proposition 1, analytically approximates the law of motion of the changed variable $z_{t}^{\mathrm{f}} \equiv \beta \exp \left(\theta x_{t}\right)\left(y_{t}^{\mathrm{f}}+1\right)$ using the exponential form

$$
\underbrace{\beta\left(\frac{d_{t}}{d_{t-1}}\right)^{1-\alpha}\left(\frac{p_{t}^{\mathrm{f}}}{d_{t}}+1\right)}_{z_{t}^{\mathrm{f}}}=\exp \left[a_{0}+a_{1}\left(x_{t}-\bar{x}\right)\right],
$$

which involves only two Taylor-series coefficients, $a_{0}$ and $a_{1}$. The approximation in Proposition 1 exploits the curvature of the exponential function rather than relying on a high-order polynomial in $\left(x_{t}-\bar{x}\right)$ to capture curvature.

We can recover an approximate solution for the fundamental price-dividend ratio by applying the equilibrium relationship $y_{t}^{\mathrm{f}}=E_{t} z_{t+1}^{\mathrm{f}}$, yielding

$$
y_{t}^{\mathrm{f}}=E_{t} z_{t+1}^{\mathrm{f}}=\exp \left[a_{0}+a_{1} \rho\left(x_{t}-\bar{x}\right)+\frac{1}{2}\left(a_{1}\right)^{2} \sigma_{\varepsilon}^{2}\right] \text {. }
$$

The above equation illustrates why it is difficult for the fundamental solution to capture the high volatility and persistence of the price-dividend ratio observed in the data. The equation shows that $y_{t}^{\mathrm{f}}$ will be constant if either $a_{1}$ or $\rho$ is equal to zero. Proposition 1 shows that $a_{1}$ will be close to zero for risk coefficients near unity, representing logarithmic utility. The value of $\rho$ is pinned down by the autocorrelation of consumption growth, which is also close to zero in long-run U.S. data. To generate high volatility and persistence in $y_{t}^{\mathrm{f}}$, the model requires a large risk coefficient combined with a persistent process for consumption/dividend growth.

\footnotetext{
${ }^{7}$ See Calin, et. al (2005), Table 1, p. 977.
} 
Alternatively, volatility and persistence in the model can be magnified by allowing deviations from full-rationality. For example, Barsky and Delong (1993) assume that agents construct a time-varying estimate of the parameter $\bar{x}$ using an exponentially-weighted moving average of past observed growth rates. They show that the perception of shifting mean growth rates can generate long swings in the model price-dividend ratio.

Figure 1 compares the approximate and exact analytical solutions for two different calibrations of the model. Throughout the paper, the agent's discount factor is set equal to $\beta=0.958$, a reasonable value for annual time periods. In panel (a), the risk coefficient is set equal to $\alpha=1.5$ and the consumption growth process is calibrated to match the mean, standard deviation, and first-order autocorrelation of U.S. annual data for the growth of real per capita consumption of nondurables and services from 1890 to $2004 .^{8}$ This procedure yields $\bar{x}=0.0206, \sigma_{\varepsilon}=0.0354$, and $\rho=-0.1$. In panel (b), the risk coefficient is increased to $\alpha=10$ while the persistence parameter for consumption growth is increased to $\rho=0.5$, with the value of $\sigma_{\varepsilon}$ adjusted downward to maintain the same volatility of consumption growth as in panel (a).

In panel (a) of Figure 1, the approximate solution is virtually indistinguishable from the exact fundamental solution. For this calibration, the standard deviation of the fundamental price dividend ratio is tiny - only 0.03 versus a whopping 13.8 in long-run U.S. data. In panel (b), where the model calibration is less plausible, the price dividend ratio is more volatile, but still well below the U.S. value. In this case, the approximate solution is somewhat less accurate, exhibiting a root mean squared percentage error of $7.8 \%$. Collard and Juillard (2001) also find that approximation errors increase with risk aversion and the persistence of the consumption growth process. A more accurate approximation could be obtained by increasing the order of the polynomial that appears inside the exponential function on the right-side of equation (14). Experiments with the model show that a quadratic polynomial inside the exponential is successful in reducing the approximation error to nearly zero for the calibration of panel (b).

As shown in the appendix, the approximate fundamental solution can be used to derive the following expressions for the unconditional moments of the asset pricing variables

$$
\begin{aligned}
& E\left[\log \left(y_{t}^{\mathrm{f}}\right)\right]=a_{0}+\frac{1}{2}\left(a_{1}\right)^{2} \sigma_{\varepsilon}^{2}, \\
& \operatorname{Var}\left[\log \left(y_{t}^{\mathrm{f}}\right)\right]=\frac{\left(a_{1} \rho\right)^{2} \sigma_{\varepsilon}^{2}}{1-\rho^{2}}, \\
& E\left[\log \left(R_{t+1}^{\mathrm{f}}\right)\right]=-\log (\beta)+\alpha \bar{x}-\frac{1}{2}\left(a_{1}\right)^{2} \sigma_{\varepsilon}^{2}, \\
& \operatorname{Var}\left[\log \left(R_{t+1}^{\mathrm{f}}\right)\right]=\left[\frac{\alpha^{2}}{1-\rho^{2}}+\left(a_{1}\right)^{2}+2 \alpha a_{1}\right] \sigma_{\varepsilon}^{2} .
\end{aligned}
$$

Given equations (16) through (19), the unconditional moments of $y_{t}^{\mathrm{f}}$ and $R_{t+1}^{\mathrm{f}}$ can be computed

\footnotetext{
${ }^{8}$ Long-run annual data for U.S. consumption and U.S. stock market variables are from Robert Shiller's website: http://www.econ.yale.edu/ shiller/.
} 
by making use of the properties of the log-normal distribution. ${ }^{9}$

\section{Rational Bubble Solutions}

The present-value pricing equation (9) imposes a no-arbitrage condition across all future time periods whereas equation (8) imposes a no-arbitrage condition only from period $t$ to $t+1$. Since equation (8) does not enforce a transversality condition, it admits solutions where $z_{t}$ can deviate from the fundamentals-based value. These so-called "rational bubble" solutions have been proposed as a way to account for the empirical observation that stock prices appear to be excessively volatile relative to a discounted stream of dividends or cash flows. The underlying assumption is that agents are forward-looking, but not to the extreme degree implied by the transversality condition.

Tirole (1982, 1985), Santos and Woodford (1997), Kamigashi (1998), and Montrucchio and Pivileggi (2001) all discuss the many theoretical caveats that govern the existence of rational bubbles in an intertemporal competitive equilibrium. A basic intuition is that rational bubbles can usually be ruled out for the simple reason that, if a bubble existed, then an infinitely-lived agent could achieve a gain by permanently selling shares at the bubble price and then foregoing dividends on those shares. Since the rational bubble solution assumes $s_{t}=1$ for all $t$, the solution fails to maximize infinite-horizon utility as implicitly required by the rational equilibrium concept. In light of such arguments, the term "rational bubble" should perhaps be considered a misnomer. Nevertheless, so-called rational bubbles can still be viewed as a possible descriptive model of asset pricing, even if these solutions do not maximize infinite-horizon utility. Along these lines, LeRoy (2004, p. 801), remarks "It is a testament to economists' capacity for abstraction that they have accepted without question that an intricate theoretical argument against bubbles has somehow migrated from the pages of Econometrica to the floor of the New York Stock Exchange."

The forecast variable $z_{t}$ that appears in equation (8) can be disaggregated as follows

$$
z_{t}=z_{t}^{\mathrm{f}}+z_{t}^{\mathrm{b}}
$$

where $z_{t}^{\mathrm{f}}$ satisfies the present-value pricing equation (9) and hence also satisfies (8). The bubble component of the forecast variable is defined as $z_{t}^{\mathrm{b}} \equiv \beta \exp \left(\theta x_{t}\right) y_{t}^{\mathrm{b}}$, where $y_{t}^{\mathrm{b}}$ is the bubble component of the price-dividend ratio. Substituting equation (20) into (8) yields the following expectational difference equation that governs the evolution of the bubble component

$$
z_{t}^{\mathrm{b}}=\beta \exp \left(\theta x_{t}\right) E_{t} z_{t+1}^{\mathrm{b}} .
$$

Together, equations (8) and (21) imply

$$
\underbrace{E_{t} z_{t+1}}_{y_{t}}=\underbrace{E_{t} z_{t+1}^{\mathrm{f}}}_{y_{t}^{\mathrm{f}}}+\underbrace{E_{t} z_{t+1}^{\mathrm{b}}}_{y_{t}^{\mathrm{b}}},
$$

which shows that $E_{t} z_{t+1}$ is the sum of two separate forecasts that pertain to the fundamental and bubble components, respectively.

\footnotetext{
${ }^{9}$ If a random variable $w_{t}$ is $\log$-normally distributed, then $E\left(w_{t}\right)=\exp \left\{E\left[\log \left(w_{t}\right)\right]+\frac{1}{2} \operatorname{Var}\left[\log \left(w_{t}\right)\right]\right\}$ and $\operatorname{Var}\left(w_{t}\right)=E\left(w_{t}\right)^{2}\left\{\exp \left(\operatorname{Var}\left[\log \left(w_{t}\right)\right]\right)-1\right\}$.
} 


\subsection{Continuum of Intrinsic Rational Bubbles}

The typical rational bubble solution requires the equity price to grow faster than dividends in perpetuity, i.e., the bubble component of the price-dividend ratio exhibits positive drift. The following proposition shows that positive-drift bubbles are actually a special case along a continuum of rational bubble equilibria.

Proposition 2. There exists a continuum of intrinsic rational bubbles of the form

$$
z_{t}^{\mathrm{b}}=z_{t-1}^{\mathrm{b}} \exp \left[\lambda_{0}+\lambda_{1}\left(x_{t}-\bar{x}\right)+\lambda_{2}\left(x_{t-1}-\bar{x}\right)\right], \quad z_{0}^{\mathrm{b}}>0,
$$

where $\lambda_{0}, \lambda_{1}$, and $\lambda_{2}$ are any three constants that satisfy the following two equilibrium conditions

$$
\begin{aligned}
& \frac{1}{2}\left(\lambda_{1}\right)^{2} \sigma_{\varepsilon}^{2}+\theta \bar{x}+\log (\beta)+\lambda_{0}=0, \\
& \lambda_{2}=-\left(\rho \lambda_{1}+\theta\right) .
\end{aligned}
$$

Proof: See appendix.

The proof of Proposition 2 shows that the results are the same, regardless of whether the agent is assumed to make use of the contemporaneous or lagged realization of $z_{t}^{\mathrm{b}}$ when forming the rational expectation $E_{t} z_{t+1}^{\mathrm{b}}$. A continuum of solutions exists because the agent's forecast rule for $E_{t} z_{t+1}^{\mathrm{b}}$ is overparameterized, relative to what is needed to satisfy the intertemporal no-arbitrage condition (21). ${ }^{10}$

Given $z_{t}^{\mathrm{b}}$, we can recover the bubble component of the price-dividend ratio by applying the definitional relationship $y_{t}^{\mathrm{b}}=\beta^{-1} \exp \left(-\theta x_{t}\right) z_{t}^{\mathrm{b}}$, yielding

$$
y_{t}^{\mathrm{b}}=y_{t-1}^{\mathrm{b}} \exp \left[\lambda_{0}+\left(\lambda_{1}-\theta\right)\left(x_{t}-\bar{x}\right)-\rho \lambda_{1}\left(x_{t-1}-\bar{x}\right)\right], \quad y_{0}^{\mathrm{b}}>0,
$$

where I have made the substitution $\lambda_{2}=-\left(\rho \lambda_{1}+\theta\right)$. From equation (23), we see that the rational bubble must always be positive and must exist from the first day of trading onwards, as noted originally by Diba and Grossman (1988). Defining the stochastic bubble drift rate as $\mu_{t}^{\mathrm{b}} \equiv \log \left(y_{t}^{\mathrm{b}} / y_{t-1}^{\mathrm{b}}\right)$, we have

$$
\begin{aligned}
& E\left(\mu_{t}^{\mathrm{b}}\right)=\lambda_{0}=-\log (\beta)-\theta \bar{x}-\frac{\left(\lambda_{1}\right)^{2} \sigma_{\varepsilon}^{2}}{2} \\
& \operatorname{Var}\left(\mu_{t}^{\mathrm{b}}\right)=\left[\left(\lambda_{1}-\theta\right)^{2}+\left(\rho \lambda_{1}\right)^{2}-2 \rho^{2} \lambda_{1}\left(\lambda_{1}-\theta\right)\right] \frac{\sigma_{\varepsilon}^{2}}{1-\rho^{2}} .
\end{aligned}
$$

The bubble is "intrinsic" because solution is driven solely by fundamentals; there are no extraneous sunspot variables. The first equilibrium condition relates the drift rate $\lambda_{0}$ to the fundamental response parameter $\lambda_{1}$. The second equilibrium condition relates $\lambda_{1}$ to the other

\footnotetext{
${ }^{10}$ Even higher degrees of overparameterization could of course be considered by introducing additional terms such as $\lambda_{3}\left(x_{t-2}-\bar{x}\right)$ inside the exponential function in the law of motion for $z_{t}^{\mathrm{b}}$.
} 
fundamental response parameter $\lambda_{2}$. If $\lambda_{0} \leq 0$, the magnitude of $\lambda_{1}$ must be larger to satisfy the first equilibrium condition. Intuitively, an increase in the magnitude of $\lambda_{1}$ raises the value of $E_{t} z_{t+1}^{\mathrm{b}}$ via Jensen's inequality, thereby allowing equation (21) to be satisfied with a zero or negative drift rate.

\subsection{Special Cases}

If we impose an arbitrary restriction on either $\lambda_{0}, \lambda_{1}$, or $\lambda_{2}$, then the values of the remaining two constants are pinned down by the two equilibrium conditions in Proposition 2. For example, by imposing $\lambda_{0}=\left(\lambda_{1}+\lambda_{2}\right) \bar{x}$, we can recover a generalized version of the intrinsic rational bubble solution derived by Froot and Obstfeld (1991). These authors considered the special case of $\rho=0$ and $\alpha=0$ (such that $\theta=1$ ). ${ }^{11}$ The Froot-Obstfeld intrinsic rational bubble takes the form

$$
\begin{aligned}
y_{t}^{\mathrm{b}} & =y_{t-1}^{\mathrm{b}} \exp \left[\left(\lambda_{1}-\theta\right) x_{t}-\rho \lambda_{1} x_{t-1}\right], \quad y_{0}^{\mathrm{b}}>0, \\
& =\frac{\eta}{\beta}\left[\frac{d_{t}^{\lambda_{1}-\theta}}{d_{t-1}^{\rho \lambda_{1}}}\right],
\end{aligned}
$$

where $d_{t}$ is the level of real dividends, $\eta$ is an arbitrary positive constant that determines $y_{0}^{\mathrm{b}}$, and $\lambda_{1}$ is a root of the quadratic equation

$$
\frac{1}{2}\left(\lambda_{1}\right)^{2} \sigma_{\varepsilon}^{2}+\lambda_{1} \bar{x}(1-\rho)+\log (\beta)=0 .
$$

The quadratic equation (27) that determines the value of $\lambda_{1}$ has two roots - one positive and one negative. The positive root is associated with an expanding bubble $\lambda_{0}>0$ while the negative root is associated with a collapsing bubble $\lambda_{0}<0$. A collapsing bubble will become vanishingly small as $t \rightarrow \infty$, so attention is typically restricted to the positive root. ${ }^{12}$ Starting from an arbitrarily small positive value $y_{0}^{\mathrm{b}}>0$, the positive root solution predicts that pricedividend ratio $y_{t}=y_{t}^{\mathrm{f}}+y_{t}^{\mathrm{b}}$ will increase without bound, never returning to the vicinity of the fundamental value $y_{t}^{\mathrm{f}}$.

Figure 2 plots the U.S. price-dividend ratio from 1871 to 2008 together with an estimated exponential time trend. The estimated annual drift rate is 0.010 (s.e. $=0.0009$ ). If this trend were to continue indefinitely, as implied by a rational bubble with drift, then the U.S. ratio would double every 72 years.

For the baseline calibration used in panel (a) of Figure 1, the positive root solution of equation (27) is $\lambda_{1}=1.806$. The solution yields a mean drift rate rate of 0.051 from equation (24), which implies a doubling time of only 14 years. A smaller predicted drift rate and a longer predicted doubling time could be obtained by increasing the calibrated value of $\beta$.

Froot and Obstfeld (1991, p. 1190) acknowledge that "It is difficult to believe that the market is literally stuck for all time on a path along which price-dividend ratios eventually

\footnotetext{
${ }^{11}$ Bidarkota and Dupoyet (2007) generalize the Froot-Obstfeld solution to allow for non-Gaussian shocks.

${ }^{12}$ The sum and product of expanding and collapsing bubble components can also be valid solutions to equation (21). Ikeda and Shibata (1992) examine bubble solutions of this type.
} 
explode." They argue, however, that explosive price-dividend ratios would not necessarily be observed over a finite sample period. Wu (1997) finds empirical support for the Froot-Obstfeld model in accounting for the volatility of the real S\&P 500 index over the period 1871 to 1992. Driffill and Sola (1998) augment the Froot-Obstfeld model to allow for regime-switching dividends. They argue that the incremental explanatory contribution of the expanding bubble component is low, relative to the regime-switching fundamentals. Their data set only extends through 1988, however, and thus does not include the dramatic, bubble-like rise in the U.S. price-dividend ratio that appears towards the end of the sample in Figure 2.

Once again starting from Proposition 2 but now imposing the restriction $\lambda_{0}=0$, we obtain the following intrinsic rational bubble solution where the mean drift rate is zero by construction.

$$
\begin{aligned}
& y_{t}^{\mathrm{b}}=y_{t-1}^{\mathrm{b}} \exp \left[\left(\lambda_{1}-\theta\right)\left(x_{t}-\bar{x}\right)-\rho \lambda_{1}\left(x_{t-1}-\bar{x}\right)\right], \quad y_{0}^{\mathrm{b}}>0, \\
& \text { where } \quad \lambda_{1}= \pm \sqrt{\frac{2 \log (1 / \beta)-2 \theta \bar{x}}{\sigma_{\varepsilon}^{2}}} .
\end{aligned}
$$

For the baseline calibration, the roots are $\lambda_{1}= \pm 9.214$. From equation (25), the volatility of the stochastic drift rate depends not only on $\lambda_{1}$, but also on the risk coefficient $\alpha$. The positive root solution has higher volatility than the negative root solution for $\alpha>1$, but the reverse is true for $\alpha<1$. Both solutions exhibit more volatility as risk aversion increases.

Other rational bubble solutions can be constructed by imposing the restriction that either $\lambda_{1}$ or $\lambda_{2}$ is zero, or say, by imposing $\lambda_{1}=\lambda_{2}$. The volatility of the bubble drift rate $\operatorname{Var}\left(\mu_{t}^{\mathrm{b}}\right)$ can be minimized by imposing $\lambda_{1}=\theta$. A so-called "time bubble" occurs when $\operatorname{Var}\left(\mu_{t}^{\mathrm{b}}\right)=0$. If $\rho=0$, a time bubble can be constructed by setting $\lambda_{1}=\theta$. If $\rho \neq 0$ and $\alpha=1$ (such that $\theta=0)$, a time bubble can be constructed by setting $\lambda_{2}=0$.

\section{A Near-Rational Asset Pricing Solution}

All of the rational bubble solutions derived in the previous section imply non-stationary behavior of the price-dividend ratio. The solutions require the representative agent to construct both a fundamental forecast $E_{t} z_{t+1}^{\mathrm{f}}$ and bubble forecast $E_{t} z_{t+1}^{\mathrm{b}}$ each period. Furthermore, the model is silent on how agents would coordinate on a particular rational bubble solution among a continuum of available solutions.

As an alternative to a rational bubble, this section presents a near-rational asset pricing solution that: (1) requires the agent to construct only a single forecast each period, (2) involves a parsimonious forecast rule that is parameterized by matching the moments of the observable data, and (3) yields a stationary, but highly persistent nonlinear law of motion for the pricedividend ratio.

I assume that the agent's perceived law of motion (PLM) for the total composite variable $z_{t}=z_{t}^{\mathrm{f}}+z_{t}^{\mathrm{b}}$ is given by

$$
z_{t}=z_{t-1} \exp \left[b\left(x_{t}-\bar{x}\right)\right], \quad z_{0}>0
$$


which is a geometric random walk without drift. The functional form of the PLM bears similarity to the approximate fundamental solution from Proposition 1 and a driftless rational bubble solution with $\lambda_{0}=0$ from Proposition 2. For an agent with limited computational resources, equation (29) is and attractive candidate PLM because it allows for nonstationary bubble behavior and involves only a single parameter $b$ that can be readily estimated from observable data. The estimated version of the PLM can be used to construct a single forecast that predicts the movement of the total asset price (fundamental plus bubble).

In constructing the subjective forecast $\widehat{E}_{t} z_{t+1}$, I assume that the agent cannot make use of the contemporaneous realization $z_{t}$, but rather uses the lagged realization $z_{t-1}$. Use of the lagged realization ensures that the forecast is "operational." Since equation (8) implies that $z_{t}$ depends on the agent's own forecast, it is not clear how the agent could make use of $z_{t}$ when constructing the forecast in real-time. A lagged information assumption is commonly used in adaptive learning models because it avoids simultaneity in the determination of the actual and expected values of the forecast variable.

As in a rational solution, I assume that the representative agent is endowed with the knowledge of the stochastic process for dividends. The underlying assumption is that enough time has elapsed for the agent to correctly identify the stochastic process from observable data. With the above assumptions, the PLM can be iterated ahead two periods to compute the following subjective forecast:

$$
\widehat{E}_{t} z_{t+1}=z_{t-1} \exp \left[b(1+\rho)\left(x_{t}-\bar{x}\right)+\frac{1}{2} b^{2} \sigma_{\varepsilon}^{2}\right],
$$

where the exponential term can be interpreted as a time-varying extrapolation factor applied to the most recent observation. ${ }^{13}$ For comparison, a rational forecast in the presence of a driftless bubble $\left(\lambda_{0}=0\right)$ would take the form

$$
\begin{aligned}
E_{t} z_{t+1}= & \underbrace{\exp \left[a_{0}+a_{1} \rho\left(x_{t}-\bar{x}\right)+\frac{1}{2}\left(a_{1}\right)^{2} \sigma_{\varepsilon}^{2}\right]}_{E_{t} z_{t+1}^{\mathrm{f}}} \\
& +\underbrace{z_{t-1}^{\mathrm{b}} \exp \left\{\left[\lambda_{1}(1+\rho)+\lambda_{2}\right]\left(x_{t}-\bar{x}\right)+\lambda_{2}\left(x_{t-1}-\bar{x}\right)+\frac{1}{2}\left(\lambda_{1}\right)^{2} \sigma_{\varepsilon}^{2}\right\}}_{E_{t} z_{t+1}^{\mathrm{b}}} .
\end{aligned}
$$

where, for symmetry, I have assumed that the rational bubble forecast $E_{t} z_{t+1}^{\mathrm{b}}$ makes use of the lagged realization $z_{t-1}^{\mathrm{b}}$. Notice that the rational bubble forecast also involves the application of a time-varying extrapolation factor to the recent observation $z_{t-1}^{\mathrm{b}}$. Not counting $\bar{x}, \rho$, and $\sigma_{\varepsilon}$ which are presumed known, the rational forecast rule (31) involves four separate parameters $\left(a_{0}, a_{1}, \lambda_{1}\right.$, and $\left.\lambda_{2}\right)$, as opposed to the subjective forecast rule (30) which involves only a single parameter $b$. An agent with limited computational resources might be inclined to adopt the more parsimonious forecast rule (30).

\footnotetext{
${ }^{13}$ Lansing $(2006)$ considers a model in which the agent's PLM is given by $z_{t}=z_{t-1} \exp \left(v_{t}\right)$, where $v_{t} \sim$ $N\left(0, \sigma_{v}^{2}\right)$ is a perceived exogenous shock that is unrelated to consumption/dividend growth. In this case, the extrapolation factor is constant rather than time-varying.
} 
Substituting the subjective forecast rule (30) into equation (8) in place of a rational forecast yields the following actual law of motion (ALM):

$$
z_{t}=\beta \exp \left(\theta x_{t}\right)\left\{z_{t-1} \exp \left[b(1+\rho)\left(x_{t}-\bar{x}\right)+\frac{1}{2} b^{2} \sigma_{\varepsilon}^{2}\right]+1\right\},
$$

which is nonlinear and autoregressive. The corresponding ALM for the price-dividend ratio $y_{t}$ can be recovered from the above expression by making use of the near-rational equilibrium relationship $y_{t}=\widehat{E}_{t} z_{t+1}$, where $\widehat{E}_{t} z_{t+1}$ is given by equation (30) with $z_{t-1}=\beta \exp \left(\theta x_{t-1}\right)\left(y_{t-1}+1\right)$. This procedure yields

$$
y_{t}=\left(y_{t-1}+1\right) \beta \exp \left[b(1+\rho)\left(x_{t}-\bar{x}\right)+\theta x_{t-1}+\frac{1}{2} b^{2} \sigma_{\varepsilon}^{2}\right],
$$

which is also nonlinear and autoregressive. The stationarity properties of the price-dividend ratio depend on the value of the forecast parameter $b$. For comparison, equation (29) can be converted into the following PLM for the price-dividend ratio

$$
y_{t}=\left(y_{t-1}+1\right) \exp \left[(b-\theta)\left(x_{t}-\bar{x}\right)+\theta\left(x_{t-1}-\bar{x}\right)\right]-1,
$$

which is similar, but not identical, to the form of the ALM (33).

\subsection{Near-Rational Equilibrium}

This section derives a near-rational, "restricted perceptions equilibrium" in which the forecast parameter $b$ is pinned down using the moments of observable data. ${ }^{14}$ Since the agent's PLM (29) implies that $z_{t}$ is nonstationary, it is natural to assume that the agent's forecast rule is parameterized to match the covariance of $\Delta \log \left(z_{t}\right)$ and $x_{t}$, where $\Delta \log \left(z_{t}\right) \equiv \log \left(z_{t} / z_{t-1}\right)$.

The PLM implies that $b$ is given by

$$
b=\frac{\operatorname{Cov}\left[\Delta \log \left(z_{t}\right), x_{t}\right]}{\operatorname{Var}\left(x_{t}\right)}
$$

where both $\operatorname{Cov}\left[\Delta \log \left(z_{t}\right), x_{t}\right]$ and $\operatorname{Var}\left(x_{t}\right)$ can be computed from observable data. An analytical expression for the observable covariance can be derived using the following loglinear approximation to the nonlinear ALM (32):

$$
z_{t} \simeq z_{t-1}^{k} \bar{z}^{1-k} \exp \left[m\left(x_{t}-\bar{x}\right)\right]
$$

where $k, m$, and $\bar{z} \equiv \exp \left(E\left[\log \left(z_{t}\right)\right]\right)$ are Taylor-series coefficients. If $k=1$ and $m=b$, then the approximate ALM (36) will coincide exactly with the PLM (29). Straightforward computations yield the following expressions for the Taylor-series coefficients

$$
\begin{aligned}
k & =\beta \exp \left[\theta \bar{x}+\frac{1}{2} b^{2} \sigma_{\varepsilon}^{2}\right] \\
m & =\theta+b(1+\rho) \beta \exp \left[\theta \bar{x}+\frac{1}{2} b^{2} \sigma_{\varepsilon}^{2}\right] \\
\bar{z} & =\frac{\beta \exp (\theta \bar{x})}{1-\beta \exp \left[\theta \bar{x}+\frac{1}{2} b^{2} \sigma_{\varepsilon}^{2}\right]},
\end{aligned}
$$

\footnotetext{
${ }^{14}$ The restricted perceptions equilibrium concept is described in Evans and Honkapohja (2001, Chapter 13).
} 
which all depend in a nonlinear way on the subjective forecast parameter $b$. The approximate law of motion of $\Delta \log \left(z_{t}\right)$ can be computed directly from equation (36), which in turn yields the following expression for the relevant covariance

$$
\operatorname{Cov}\left[\Delta \log \left(z_{t}\right), x_{t}\right]=\left[\frac{(1-\rho) m}{1-\rho k}\right] \operatorname{Var}\left(x_{t}\right),
$$

which is nonlinear in $b$ via the expressions for $k$ and $m$. Details are contained in the appendix. Equations (35) and (40) can be combined to form the following definition of equilibrium.

Definition 1. A near-rational "restricted perceptions equilibrium" is defined as a perceived law of motion (29), an approximate actual law of motion (36), and a subjective forecast rule parameter $b$, such that the equilibrium value $b$ is given by the fixed point of the nonlinear map

$$
b=T(b) \equiv \frac{(1-\rho) m(b)}{1-\rho k(b)},
$$

where $k(b)$ and $m(b)$ are parameters of the approximate actual law of motion that depend on $b$, as given by equations (37) and (38), provided that $0 \leq k(b) \leq 1$.

In equilibrium, we require $0 \leq k(b) \leq 1$ so that $\Delta \log \left(z_{t}\right)$ remains stationary, thereby allowing $\operatorname{Cov}\left[\Delta \log \left(z_{t}\right), x_{t}\right]$ to be computed from observable data. If $0 \leq k(b)<1$, then $\log \left(z_{t}\right)$ and $\log \left(y_{t}\right)$ are stationary.

The approximate ALM (36) can be used to derive the following analytical expressions for the unconditional moments of the asset pricing variables

$$
\begin{aligned}
E\left[\log \left(y_{t}\right)\right] & =\log \left[\frac{k(b)}{1-k(b)}\right], \quad 0 \leq k(b)<1, \\
E\left[\log \left(R_{t+1}\right)\right] & =-\log (\beta)+\alpha \bar{x}-\frac{1}{2} b^{2} \sigma_{\varepsilon}^{2},
\end{aligned}
$$

where $k(b)$ is given by equation (37). Notice that the expression for $E\left[\log \left(R_{t+1}\right)\right]$ has the same form as the fundamental mean return $E\left[\log \left(R_{t+1}^{\mathrm{f}}\right)\right]$ given by equation (18), except that $\left(a_{1}\right)^{2}$ is replaced here by $b^{2}$. At the baseline calibration, we have $a_{1}=-0.457$. As shown in the next section, the near-rational equilibrium yields $b=-3.695$, which causes the near-rational mean return to be below that of the fundamental mean return. This result can be traced to a small degree of excess optimism in the near-rational forecast rule. Excess optimism has an effect on the mean return that is similar to increasing patience about future payoffs via a higher value for the discount factor $\beta$. The appendix outlines the derivation of analytical expressions for the unconditional variances $\operatorname{Var}\left[\log \left(y_{t}\right)\right]$ and $\operatorname{Var}\left[\log \left(R_{t+1}\right)\right]$.

\subsection{Numerical Solution for the Equilibrium}

The complexity of the nonlinear map $b=T(b)$ necessitates a numerical solution for the equilibrium. Using the baseline calibration, panel (a) of Figure 3 plots plots $T(b)$ over the range $-25 \leq b \leq 20$. There are three fixed points. At the middle fixed point, we have $b=-3.695$. From panel (b), we see that only the middle fixed point yields a stationary equilibrium such 
that $0 \leq k(b)<1$. When $b=-3.695$, the autoregressive root in the approximate ALM (36) is $k=0.956$. The corresponding response coefficient on $\left(x_{t}-\bar{x}\right)$ in the ALM is $m=-3.680$. Recall that when $k=1$ and $m=b$, the approximate ALM (36) coincides exactly with the $\operatorname{PLM}$ (29). At the middle fixed point, we have $k \simeq 1$ and $m \simeq b$, such that the equilibrium can be described as "near-rational."

Making use of the approximate ALM (36) and the subjective forecast rule (30), the percentage forecast error observed by the agent is given by

$$
\begin{aligned}
e r r_{t+1} & =\log \left(\frac{z_{t+1}}{\widehat{E}_{t} z_{t+1}}\right) \\
& =\log \left\{\frac{z_{t}^{k} \bar{z}^{1-k} \exp \left[m\left(x_{t+1}-\bar{x}\right)\right]}{z_{t-1} \exp \left[b(1+\rho)\left(x_{t}-\bar{x}\right)+\frac{1}{2} b^{2} \sigma_{\varepsilon}^{2}\right]}\right\},
\end{aligned}
$$

where $k$ and $m$ are given by equations (37) and (38). Recalling that $\bar{z}=\exp \left(E\left[\log \left(z_{t}\right)\right]\right)$, the above equation implies $E\left(e r r_{t+1}\right)=-b^{2} \sigma_{\varepsilon}^{2} / 2$. At the equilibrium value $b=-3.695$, with $\sigma_{\varepsilon}=0.0354$, we have $E\left(e r r_{t+1}\right)=-0.009$. In contrast, the approximate fundamental solution implies $E\left(e r r_{t+1}^{\mathrm{f}}\right)=-0.0001$ for the same calibration.

Equation (43) can be used to derive an analytical expression for the autocorrelation of percentage forecast errors $\operatorname{Corr}\left(e r r_{t+1}, e r r_{t}\right)$, as outlined in the appendix. The value of $\operatorname{Corr}\left(\operatorname{err}_{t+1}, e r r_{t}\right)$ is plotted in panel (c) of Figure 3. At the equilibrium value $b=-3.695$, the correlation coefficient is 0.02 . The near-zero autocorrelation of the forecast errors makes it difficult for the agent to detect a misspecification of the subjective forecast rule (30). Panel (d) of Figure 3 plots the root mean squared percentage forecast error (RMSPE), defined as $\left[E\left(e r r_{t+1}^{2}\right)\right]^{0.5}$ At the equilibrium value, we have $R M S P E=13.5 \%$. Since $R M S P E$ could be reduced by shrinking the magnitude of the subjective forecast parameter $b$, the agent can be viewed as exhibiting overreaction to the fundamental term $\left(x_{t}-\bar{x}\right) .{ }^{15}$ The fundamental solution implies $R M S P E^{\mathrm{f}}=1.62 \%$ for the same calibration.

\subsection{Real-Time Learning}

Figure 4 illustrates the convergence properties of the near-rational equilibrium under real-time learning. Recall that the fixed point of the nonlinear map $b=T(b)$ is computed using the approximate population covariance statistic $\operatorname{Cov}\left[\Delta \log \left(z_{t}\right), x_{t}\right]$, as given by equation (40). This statistic presumes a fixed forecast parameter $b$. However, in a real-time learning environment where the forecast parameter evolves over time, the agent will only have knowledge of a sample covariance which, in turn, is influenced by the trajectory of the forecast parameter.

The real-time learning algorithm makes use of the nonlinear ALM for $z_{t}$, equation (32). The forecast parameter $b_{t-1}$ that is used in computing $z_{t}$ is estimated each period (starting at $t=5$ ) using equation (35) with an expanding window of data that runs through time $t-1$. The stochastic process for dividends (3) is presumed known by the agent. Figure 4

\footnotetext{
${ }^{15}$ Lansing (2009) considers the welfare cost of speculative overreaction in a production economy with endogenous long-run consumption growth.
} 
plots twelve learning simulations of length 5000 periods using a starting value for the forecast parameter that is set \pm 5 above or below the theoretical equilibrium value for the first five periods. The starting value $z_{0}$ is computed from equation (39) with $b=b_{0}$. The end-ofsimulation values are clustered in the range where the (approximate) theoretical map $T(b)$ lies very close to the 45-degree line. Given the shape of the map and the nonlinear form of the ALM (32), a small amount of sampling variation in the covariance statistic can affect the speed of convergence and the end-of-simulation value. For the twelve learning simulations shown, the average end-of-simulation value is -3.752 , which is close to the theoretical equilibrium value of $b=-3.695$ computed using the approximate ALM (36). The simulations demonstrate that the near-rational equilibrium is learnable.

The technical condition that must be satisfied for learnability (or "E-stability") is $T^{\prime}(b)<$ $1 .{ }^{16}$ In the special case of iid consumption growth $(\rho=0)$ and logarithmic utility $(\theta=0)$, the expression for $T(b)$ reduces to

$$
T(b)=b \beta \exp \left[b^{2} \sigma_{\varepsilon}^{2} / 2\right],
$$

which has three fixed points given by $b=\left\{0, \pm \sqrt{2 \log (1 / \beta) / \sigma_{\varepsilon}^{2}}\right\}$. It is easy to check that the middle fixed point $b=0$ satisfies the learnability condition $T^{\prime}(b)=\beta<1$, while the other two solutions yield $T^{\prime}(b)=1+b^{2} \sigma_{\varepsilon}^{2}>1$ and hence are not stable under learning. By continuity, these results extend to parameter combinations $(\rho, \theta)$ that are sufficiently close to $(0,0)$ and for starting values that lie in the basin of attraction of the middle fixed point. For the baseline calibration with $(\rho, \theta)=(-0.1,-0.5)$, the properties of the near-rational equilibrium are qualitatively similar to the special case of $(\rho, \theta)=(0,0) .^{17}$

Numerical experiments with the model show that as consumption growth becomes more persistent ( $\rho$ increases) or as the agent become more risk averse ( $\alpha$ increases), satisfying the learnability condition $T^{\prime}(b)<1$ may require the discount factor $\beta$ to remain below a threshold value. It is worth noting, however, that even when a parameter combination does not satisfy $T^{\prime}(b)<1$, it would still be possible for the agent to estimate a value of $b$ using a rolling window of past data. In this case, the learning algorithm would never converge to a fixed point, but rather, the estimated value of $b$ would drift over time, acting as an additional source of excess volatility. $^{18}$

\section{Model Simulations}

Table 1 presents unconditional moments of asset pricing variables computed from a long-run simulation of the model. The table also reports the corresponding statistics from U.S. data over the period 1871 to $2008 .{ }^{19}$ The fundamental solution is simulated using the expressions

\footnotetext{
${ }^{16}$ For details, see Evans and Honkapohja (2001, p. 39).

${ }^{17}$ I thank an anonymous referee for providing this insight.

${ }^{18}$ The learning algorithm may need to be modified in this case to include a "projection facility," which sets $b_{t}=b_{t-1}$ if the estimation procedure delivers a result that falls outside the agent's preconceived range of economically reasonable values.

${ }^{19}$ The price-dividend ratio in year $t$ is defined as the value of the S\&P 500 stock index at the beginning of year $t+1$, divided by the accumulated dividend over year $t$.
} 
in Proposition 1. Equations (26) and (28) are used to simulate the rational bubble solutions, which are superimposed on top of the fundamental solution. ${ }^{20}$ For the rational bubble solutions, the initial level of the bubble component $y_{0}^{\mathrm{b}}$ is set equal to $1 \%$ of the steady-state fundamental price-dividend ratio. For the fundamental and near-rational solutions, the initial condition is the corresponding steady-state price-dividend ratio.

The top section of Table 1 shows that the near-rational solution does an excellent job of matching the unconditional moments of the U.S. price-dividend ratio. The calibrated values of $\beta$ and $\alpha$ were chosen so that the near-rational solution comes close to matching the mean and volatility of the U.S. price-dividend ratio. ${ }^{21}$ But the near-rational solution also does a good job of matching the higher moments. In particular, the U.S. price-dividend ratio exhibits positive skewness, excess kurtosis, and strong positive serial correlation. Positive skewness and excess kurtosis suggest the presence of nonlinearities in the data. The near-rational solution is able to capture these features due to the non-linear form of the ALM for $y_{t}$, equation (33). In contrast, the fundamental solution delivers low volatility, near-zero skewness, no excess kurtosis, and weak negative serial correlation which is inherited directly from the consumption growth process with $\rho=-0.1$. The rational bubble solutions imply that the price-dividend ratio is non-stationary, so the corresponding moments do not exist.

The middle section of Table 1 compares unconditional moments for the drift rate of the price-dividend ratio - a stationary variable for all model solutions. The mean drift rate in U.S. data is 0.004 versus a drift rate of 0.05 for the Froot-Obstfeld solution. ${ }^{22}$ The "Driftless Bubble 2" solution and the near-rational solution both produce a reasonably good match with the moments in the data.

The last section of Table 1 compares unconditional moments for the equity return. Relative to the fundamental solution, the mean return for the near-rational solution is slightly lower (6.96\% versus $7.68 \%$ ), whereas the volatility of returns is higher $(9.08 \%$ versus $4.04 \%)$. The returns generated by the near-rational solution exhibit only a small amount of positive serial correlation, albeit slightly stronger than in U.S. data.

Figure 5 plots simulated data for the different solutions of the model. The left-side panels show the price dividend ratio $y_{t}=y_{t}^{\mathrm{f}}+y_{t}^{\mathrm{b}}$, while the right-side panels show the net equity return $R_{t}-1$. The explosive price-dividend ratio in the Froot-Obstfeld solution with $\lambda_{1}>0$ can be seen in panel (a), which in the only panel to employ a logarithmic scale. In panel (b), the equity return generated by the Froot-Obstfeld solution remains stationary and exhibits time-varying volatility. In panels (c) and (e), the two driftless rational bubble solutions exhibit what can be viewed as stylized bubbles and crashes, where the price dividend ratio undergoes irregularly-spaced episodes of rapid expansions and contractions. Return volatility increases

\footnotetext{
20 "Driftless Bubble 1" refers to the solution shown in equation (28) with $\lambda_{1}>0$, while "Driftless Bubble 2" refers to the solution with $\lambda_{1}<0$.

${ }^{21}$ If the model is recalibrated with $\rho=0$ rather than $\rho=-0.1$, then the ability to match both of these moments deteriorates because either $\beta$ or $\alpha$ must be adjusted downward to ensure that the learnability condition is satisfied, as described in section 5.3 .

${ }^{22}$ In Table 1, the mean drift rate in U.S. data is estimated by taking the average of annual log changes. In Figure 2, the mean drift rate is estimated by fitting an exponential time trend through the data. The latter procedure yields a larger estimated drift rate.
} 
dramatically during these episodes, as shown in panels (d) and (f).

Table 1. Unconditional Moments

\begin{tabular}{|c|c|c|c|c|c|c|}
\hline \multirow[b]{2}{*}{ Statistic } & \multirow[b]{2}{*}{$\begin{array}{c}\text { U.S. Data } \\
1871-2008\end{array}$} & \multicolumn{5}{|c|}{ Model Simulations } \\
\hline & & $\begin{array}{l}\text { Funda- } \\
\text { mental }\end{array}$ & $\begin{array}{c}\text { Froot- } \\
\text { Obstfeld }\end{array}$ & $\begin{array}{c}\text { Driftless } \\
\text { Bubble } 1\end{array}$ & $\begin{array}{c}\text { Driftless } \\
\text { Bubble } 2\end{array}$ & $\begin{array}{c}\text { Near- } \\
\text { Rational }\end{array}$ \\
\hline$y_{t}=p_{t} / d_{t}$ & & & - & - & - & \\
\hline Mean & 26.6 & 18.4 & - & - & - & 27.1 \\
\hline Std. Dev. & 13.8 & 0.03 & - & - & - & 13.9 \\
\hline Skew. & 2.20 & -0.02 & - & - & - & 2.34 \\
\hline Kurt. & 8.21 & 3.00 & - & - & - & 11.7 \\
\hline Corr. Lag 1 & 0.93 & -0.11 & - & - & - & 0.97 \\
\hline \multicolumn{7}{|l|}{$\log \left(y_{t} / y_{t-1}\right)$} \\
\hline Mean & 0.004 & 0.000 & 0.050 & 0.000 & 0.003 & 0.000 \\
\hline Std. Dev. & 0.206 & 0.002 & 0.082 & 0.042 & 0.269 & 0.119 \\
\hline Skew. & -0.12 & 0.03 & -0.03 & 0.59 & 0.04 & 0.03 \\
\hline Kurt. & 3.19 & 2.99 & 3.00 & 125.2 & 3.89 & 3.00 \\
\hline Corr. Lag 1 & -0.07 & -0.55 & -0.03 & -0.10 & 0.00 & 0.02 \\
\hline \multicolumn{7}{|l|}{$R_{t}-1$} \\
\hline Mean & $7.84 \%$ & $7.68 \%$ & $8.06 \%$ & $7.66 \%$ & $6.59 \%$ & $6.96 \%$ \\
\hline Std. Dev & $17.8 \%$ & $4.04 \%$ & $12.7 \%$ & $6.84 \%$ & $25.9 \%$ & $9.08 \%$ \\
\hline Skew. & -0.05 & 0.09 & 0.33 & 3.69 & 0.95 & 0.28 \\
\hline Kurt. & 2.87 & 3.02 & 3.21 & 92.7 & 5.40 & 3.13 \\
\hline Corr. Lag 1 & 0.04 & -0.15 & -0.06 & -0.12 & 0.00 & 0.14 \\
\hline
\end{tabular}

Note: Model statistics are based on a 12,000 period simulation after dropping 500 periods.

Parameter values: $\bar{x}=0.0206, \sigma_{\varepsilon}=0.0354, \rho=-0.1, \alpha=1.5$, and $\beta=0.958$.

Table 2. 20-Year Rolling Volatility of Returns

\begin{tabular}{ccccccc}
\hline \hline & & \multicolumn{5}{c}{ Model Simulations } \\
\cline { 3 - 7 } Std. Dev. & U.S. Data & $\begin{array}{c}\text { Funda- } \\
\text { mental }\end{array}$ & $\begin{array}{c}\text { Froot- } \\
\text { Obstfeld }\end{array}$ & $\begin{array}{c}\text { Driftless } \\
\text { Bubble 1 }\end{array}$ & $\begin{array}{c}\text { Driftless } \\
\text { Bubble 2 }\end{array}$ & $\begin{array}{c}\text { Near- } \\
\text { Rational }\end{array}$ \\
\hline & $1871-2008$ & & & & & \\
Min 20-Yr & $12.5 \%$ & $1.77 \%$ & $3.06 \%$ & $1.77 \%$ & $0.93 \%$ & $4.41 \%$ \\
Max 20-Yr & $27.9 \%$ & $7.07 \%$ & $23.4 \%$ & $65.5 \%$ & $48.7 \%$ & $13.8 \%$ \\
Full Sample. & $17.8 \%$ & $4.04 \%$ & $12.7 \%$ & $6.84 \%$ & $25.9 \%$ & $9.08 \%$ \\
\hline
\end{tabular}

Notes: Model statistics are based on a 12,000 period simulation after dropping 500 periods.

Parameter values: $\bar{x}=0.0206, \sigma_{\varepsilon}=0.0354, \rho=-0.1, \alpha=1.5$, and $\beta=0.958$. 
In panel $(\mathrm{g})$, the near-rational price-dividend ratio exhibits pronounced low-frequency swings that are driven by random shocks impinging upon the highly-persistent, nonlinear ALM (33). The near-rational solution can also generate periods where the price-dividend ratio dips below the fundamental value. In contrast, a rational bubble solution requires the price-dividend ratio to always remain above the fundamental. ${ }^{23}$ The timing of expanding and contracting bubble episodes in panel $(\mathrm{g})$ is somewhat similar to that generated by the driftless rational bubble solution with $\lambda_{1}<0$ plotted in panel (e). Both solutions exhibit a negative response coefficient on the fundamental term $\left(x_{t}-\bar{x}\right)$ in the corresponding law of motion.

The nonlinear nature of the exact ALM (33) gives rise to time-varying return volatility, as shown in panel (h). Table 2 provides a quantitative comparison of the return volatilities in U.S. data and the various model solutions. From 1871 to 2008, the 20-year rolling standard deviation of U.S. returns varies from a minimum of $12.5 \%$ to a maximum of $27.9 \%$. The Froot-Obstfeld solution provides the best match with the data, followed by the near-rational solution.

Table 3 provides a quantitative comparison of forecast errors between the fundamental and near-rational solutions. As noted earlier, the fundamental solution delivers a lower $R M S P E$. However, the near-rational forecast errors are close to white noise at all lags - giving no discernible indication to the agent that the subjective forecast rule (30) is misspecified.

Table 3: Comparison of Percentage Forecast Errors

\begin{tabular}{ccc}
\hline \hline & \multicolumn{2}{c}{ Model Simulations } \\
Statistic & Fundamental & Near-Rational \\
\hline$E\left(e r r_{t+1}\right)$ & 0.000 & -0.010 \\
{$\left[E\left(e r r_{t+1}^{2}\right)\right]^{0.5}$} & 0.016 & 0.136 \\
$\operatorname{Corr}\left(e r r_{t+1}, e r r_{t}\right)$ & -0.01 & 0.02 \\
$\operatorname{Corr}\left(\operatorname{err}_{t+1}, \operatorname{err}_{t-1}\right)$ & -0.01 & -0.02 \\
$\operatorname{Corr}\left(\operatorname{err}_{t+1}, \operatorname{err}_{t-2}\right)$ & -0.01 & -0.01 \\
\hline
\end{tabular}

Notes: Model statistics are based on a 12,000 period simulation after dropping 500 periods.

Parameter values: $\bar{x}=0.0206, \sigma_{\varepsilon}=0.0354, \rho=-0.1, \alpha=1.5$, and $\beta=0.958$.

\subsection{Empirical Tests}

To provide a more direct empirical assessment of the near-rational solution, I regress the PLM (34) in first-difference form on U.S. data for the price-dividend ratio and per capita consumption growth over the period 1891 to 2004. The regression implements a procedure for estimating the parameter $b$, analogous to the agent's use of the covariance expression (35) in the model. For the regression, I impose $\alpha=1.5$ and $\bar{x}=0.0206 .{ }^{24}$ The regression yields $b=-1.56$ (s.e. $=0.50$ ), which is in the ballpark of the theoretical value of $b=-3.695$.

\footnotetext{
${ }^{23}$ Weil (1990) notes that a positive rational bubble can cause the equilibrium asset price to dip below the ex ante fundamental value if there is sufficient feedback from the bubble to either dividends or the discount rate.

${ }^{24}$ With these parameter restrictions, the regression equation becomes $\Delta \log \left(y_{t}+1\right)=$ $(b+0.5)\left(x_{t}-0.0206\right)-0.5\left(x_{t-1}-0.0206\right)$, where $y_{t}$ is the U.S. price-dividend ratio and $x_{t}$ is U.S. per capita consumption growth.
} 
More generally, there is a vast literature on econometric tests for the presence of bubbles. Some recent studies are closely related to the results presented here. Bohl and Siklos (2004) and Coakley and Fuertes (2006) fit nonlinear time series models to U.S. stock market valuation ratios over the period 1871 to 2001 . Both studies find evidence that valuation ratios drift upwards into bubble territory during bull markets, but these persistent departures from fundamentals are eventually eliminated via downward adjustments during bear markets. Recent empirical tests for nonstationarity of the U.S. price-dividend ratio are inconclusive. Engsted (2006) finds support for a nonstationary rational bubble in U.S. data. In contrast, a study by Koustas and Serletis (2005) rejects the rational bubble hypothesis in favor of mean-reverting behavior for the U.S. price-dividend ratio. The near-rational solution derived here predicts mean-reverting behavior for the price-dividend ratio.

In reviewing the literature on empirical tests for the presence of bubbles, Gürkaynak (2007) concludes that a sufficiently-rich fundamental model of asset prices can often fit the data equally as well as any bubble model. Cochrane (2009) argues that the concept of a bubble driven by irrational expectations of the future is observationally equivalent to a situation where the risk premium required by rational agents is temporarily low. ${ }^{25}$ But actually these two scenarios can be distinguished by examining agents' expectations about future returns. Irrationally exuberant agents would forecast high future returns following a sustained price run-up, whereas rational agents with temporarily low risk premiums would forecast low future returns. Evidence from investor survey data seems to support the former scenario. VissingJorgenson (2004) finds evidence of extrapolative expectations among investors; those who have experienced high portfolio returns in the past tend to expect higher returns in the future. Amromin and Sharpe (2009) find that household investors expect higher future returns during periods when macroeconomic conditions are expected to improve - a result which they conclude "is inconsistent with the view that stock market returns should compensate [rational] investors for exposure to macroeconomic risks."

\section{Concluding Remarks}

Theories involving departures from fully-rational behavior have long played a role in efforts to account for the behavior of asset prices. Keynes (1936, p. 156) likened the stock market to a "beauty contest" where participants devoted their efforts not to judging the underlying concept of beauty, but instead to "anticipating what average opinion expects the average opinion to be."

There are many examples in history of asset prices exhibiting sustained run-ups that are difficult to justify on the basis of economic fundamentals. The typical transitory nature of these run-ups should perhaps be viewed as a long-run victory for fundamental asset pricing theory. Still, it remains a challenge for fundamental theory to explain the ever-present volatility of asset prices within a framework of efficient capital markets. Rational bubbles are an attractive modeling device because the framework allows asset prices to exceed fundamentals

\footnotetext{
${ }^{25}$ Specifically, he remarks (p. 2) that "Crying 'bubble' is empty unless you have an operational procedure for distinguishing them from rationally low risk premiums..."
} 
while imposing a no-arbitrage condition over short time horizons. In a rational bubble solution, an asset is valued not for its cash flows, but rather for its potential to deliver capital gain - a feature that seems to fit the prevailing psychology during historical bubble episodes.

This paper demonstrated the existence of a continuum of intrinsic rational bubble solutions that satisfy a period-by-period no-arbitrage condition. When the mean drift rate of the bubble is zero by construction, the short-term prospects for capital gain derive solely from the high volatility of the bubble component. A driftless rational bubble exhibits irregularly-spaced expansions and collapses that are wholly endogenous.

Strictly speaking, rational bubbles are not fully rational because the transversality condition is not satisfied. In a world where agents' computational resources are limited, further movements away from full rationality would seem plausible. The near-rational asset pricing solution developed here is based on a parsimonious and versatile forecast rule: a geometric random walk without drift. Innovations to the geometric random walk are linked to consumption/dividend growth. When the agent's forecast rule is parameterized to match the moments of observable data, the resulting forecast errors are close to white noise. The near-rational solution does a good job of matching many quantitative features of U.S. stock market data and allows the equity price to occasionally dip below the fundamental price. 


\section{A Appendix: Derivations and Proofs}

\section{A.1 Separating Consumption from Dividends}

The Lucas (1978) model implies $c_{t}=d_{t}$ for all $t$. This section outlines a version of the model that allows $c_{t} \neq d_{t}$. The agent's first-order condition is

$$
\frac{p_{t}}{d_{t}}=E_{t}\left\{\beta\left(\frac{c_{t+1}}{c_{t}}\right)^{-\alpha}\left(\frac{d_{t+1}}{d_{t}}\right)\left(\frac{p_{t+1}}{d_{t+1}}+1\right)\right\} .
$$

The separate growth rates of consumption and dividends are now given by

$$
\begin{aligned}
\log \left(c_{t} / c_{t-1}\right) & \equiv x_{t}^{c}=\bar{x}^{c}+\rho\left(x_{t-1}^{c}-\bar{x}^{c}\right)+\varepsilon_{t}, \quad \varepsilon_{t} \sim N\left(0, \sigma_{\varepsilon}^{2}\right), \quad|\rho|<1, \\
\log \left(d_{t} / d_{t-1}\right) & \equiv x_{t}^{d}=\bar{x}^{d}+\gamma\left(x_{t}^{c}-\bar{x}^{c}\right)+v_{t} \quad v_{t} \sim N\left(0, \sigma_{v}^{2}\right),
\end{aligned}
$$

where $v_{t}$ is uncorrelated with $\varepsilon_{t}$. As before, consumption growth is described by a univariate $\mathrm{AR}(1)$ process. Deviations of dividend growth from consumption growth are governed by the parameters $\bar{x}^{d}, \gamma$, and $\sigma_{v}^{2}$. The original Lucas model with $c_{t}=d_{t}$ can be recovered by setting $\bar{x}^{d}=\bar{x}^{c}, \gamma=1$, and $\sigma_{v}=0$. For the model with $c_{t} \neq d_{t}$, these parameters are calibrated to match three moments: (1) the unconditional mean of dividend growth $E\left[\log \left(d_{t} / d_{t-1}\right)\right],(2)$ the contemporaneous correlation between dividend growth and consumption growth $\operatorname{Corr}\left(x_{t}^{d}, x_{t}^{c}\right)$, and (3) the unconditional variance of dividend growth $\operatorname{Var}\left(x_{t}^{d}\right)$. The resulting calibration formulas are

$$
\begin{aligned}
\bar{x}^{d} & =E\left[\log \left(d_{t} / d_{t-1}\right)\right], \\
\gamma & =\operatorname{Corr}\left(x_{t}^{d}, x_{t}^{c}\right)\left[\operatorname{Var}\left(x_{t}^{d}\right) / \operatorname{Var}\left(x_{t}^{c}\right)\right]^{0.5}, \\
\sigma_{v} & =\left[\operatorname{Var}\left(x_{t}^{d}\right)-\gamma^{2} \operatorname{Var}\left(x_{t}^{c}\right)\right]^{0.5} .
\end{aligned}
$$

The agent's first-order condition can be written in terms of the price-dividend ratio $y_{t}$ as follows:

$$
\begin{aligned}
y_{t} & =E_{t}\left\{\beta \exp \left[-\alpha x_{t+1}^{c}+\bar{x}^{d}+\gamma\left(x_{t+1}^{c}-\bar{x}^{c}\right)+v_{t+1}\right]\left(y_{t+1}+1\right)\right\}, \\
& =E_{t}\left\{\widetilde{\beta} \exp \left(\widetilde{\theta} \widetilde{x}_{t+1}\right)\left(y_{t+1}+1\right)\right\} \\
\text { where } \quad \widetilde{\beta} & \equiv \beta \exp \left(\bar{x}^{d}-\gamma \bar{x}^{c}\right), \quad \widetilde{\theta} \equiv \gamma-\alpha, \quad \widetilde{x}_{t} \equiv x_{t}^{c}+v_{t} / \widetilde{\theta}
\end{aligned}
$$

Making use of the above definitions, equations (A.2) and (A.3) yield the following transformed version of equation (3):

$$
\widetilde{x}_{t}=\bar{x}^{c}+\rho\left(\widetilde{x}_{t-1}-\bar{x}^{c}\right)+\omega_{t}, \quad \omega_{t} \equiv \varepsilon_{t}+\left(v_{t}-\rho v_{t-1}\right) / \widetilde{\theta}
$$

where $\omega_{t} \sim N\left(0, \sigma_{\omega}^{2}\right), \sigma_{\omega}^{2}=\sigma_{\varepsilon}^{2}+\left(1+\rho^{2}\right) \sigma_{v}^{2} / \widetilde{\theta}^{2}$, and $\operatorname{Corr}\left(\omega_{t}, \omega_{t-1}\right)=-\rho /\left(\widetilde{\theta}^{2} \sigma_{\varepsilon}^{2} / \sigma_{v}^{2}+1+\rho^{2}\right)$. 
Finally, we define $\widetilde{z}_{t} \equiv \widetilde{\beta} \exp \left(\widetilde{\theta} \widetilde{x}_{t}\right)\left(y_{t}+1\right)$ to obtain the following transformed version of equation (8):

$$
\widetilde{z}_{t}=\widetilde{\beta} \exp \left(\widetilde{\theta} \widetilde{x}_{t}\right)\left[E_{t} \widetilde{z}_{t+1}+1\right] .
$$

Thus, by an appropriate change of variables, equations (A.8) and (A.9) retain the same basic forms as equations (3) and (8), with the exception that the innovation $\omega_{t}$ is not iid, but instead exhibits serial correlation. However, for small values of $\rho$, we can make the simplifying assumption that $\operatorname{Corr}\left(\omega_{t}, \omega_{t-1}\right) \simeq 0$. With this assumption, all of the paper's theoretical results will go through when expressed in terms of the transformed variables.

\section{A.2 Proof of Proposition 1: Approximate Fundamental Solution}

Iterating ahead the conjectured law of motion for $z_{t}^{\mathrm{f}}$ and taking the conditional expectation yields

$$
E_{t} z_{t+1}^{\mathrm{f}}=\exp \left[a_{0}+\rho a_{1}\left(x_{t}-\bar{x}\right)+\frac{1}{2}\left(a_{1}\right)^{2} \sigma_{\varepsilon}^{2}\right] .
$$

Substituting the above expression into the first order condition (8) and then taking logarithms yields

$$
\begin{aligned}
\log \left(z_{t}^{\mathrm{f}}\right)=F\left(x_{t}\right)= & \log (\beta)+\theta x_{t} \\
& +\log \left\{\exp \left[a_{0}+\rho a_{1}\left(x_{t}-\bar{x}\right)+\frac{1}{2}\left(a_{1}\right)^{2} \sigma_{\varepsilon}^{2}\right]+1\right\}, \\
\simeq & a_{0}+a_{1}\left(x_{t}-\bar{x}\right),
\end{aligned}
$$

where $a_{0} \equiv E\left[\log \left(z_{t}^{\mathrm{f}}\right)\right]$ and $a_{1}$ are Taylor-series coefficients which are are given by

$$
\begin{aligned}
& F(\bar{x})=a_{0}=\log (\beta)+\theta \bar{x}+\log \left\{\exp \left[a_{0}+\frac{1}{2}\left(a_{1}\right)^{2} \sigma_{\varepsilon}^{2}\right]+1\right\} \\
& F^{\prime}(\bar{x})=a_{1}=\theta+\frac{\rho a_{1} \exp \left[a_{0}+\frac{1}{2}\left(a_{1}\right)^{2} \sigma_{\varepsilon}^{2}\right]}{\exp \left[a_{0}+\frac{1}{2}\left(a_{1}\right)^{2} \sigma_{\varepsilon}^{2}\right]+1} .
\end{aligned}
$$

Solving equation (A.12) for $a_{0}$ yields

$$
a_{0}=\log \left\{\frac{\beta \exp (\theta \bar{x})}{1-\beta \exp \left[\theta \bar{x}+\frac{1}{2}\left(a_{1}\right)^{2} \sigma_{\varepsilon}^{2}\right]}\right\},
$$

which can be substituted into equation (A.13) to yield the following nonlinear equation that determines $a_{1}$ :

$$
a_{1}=\theta+\rho a_{1} \beta \exp \left[\theta \bar{x}+\frac{1}{2}\left(a_{1}\right)^{2} \sigma_{\varepsilon}^{2}\right] .
$$

Solving equation (A.15) for $a_{1}$ yields the nonlinear equation shown in Proposition 1. There are two solutions, but only one solution satisfies the condition $\beta \exp \left[\theta \bar{x}+\frac{1}{2}\left(a_{1}\right)^{2} \sigma_{\varepsilon}^{2}\right]<1$ such that $\exp \left(a_{0}\right)=\exp \left[E \log \left(z_{t}^{\mathrm{f}}\right)\right]>0$. 


\section{A.3 Asset Pricing Moments: Fundamental Solution}

This section briefly outlines the derivation of equations (16) through (19).

Equation (16) follows directly from equation (15) by taking the unconditional expectation of $\log \left(y_{t}^{\mathrm{f}}\right)$. We have

$$
\log \left(y_{t}^{\mathrm{f}}\right)-E\left[\log \left(y_{t}^{\mathrm{f}}\right)\right]=a_{1} \rho_{1}\left(x_{t}-\bar{x}\right),
$$

which implies $\operatorname{Var}\left[\log \left(y_{t}^{\mathrm{f}}\right)\right]=\left(a_{1}\right)^{2} \rho^{2} \operatorname{Var}\left(x_{t}\right)$, as given by equation (17).

The fundamental equity return can be written as

$$
\begin{aligned}
R_{t+1}^{\mathrm{f}} & =\left(\frac{y_{t+1}^{\mathrm{f}}+1}{y_{t}^{\mathrm{f}}}\right) \exp \left(x_{t+1}\right), \\
& =\left(\frac{z_{t+1}^{\mathrm{f}}}{\beta E_{t} z_{t+1}^{\mathrm{f}}}\right) \exp \left(\alpha x_{t+1}\right),
\end{aligned}
$$

where I have eliminated $y_{t}^{\mathrm{f}}$ using the equilibrium relationship $y_{t}^{\mathrm{f}}=E_{t} z_{t+1}^{\mathrm{f}}$ and eliminated $y_{t+1}^{\mathrm{f}}$ using the definitional relationship $y_{t+1}^{\mathrm{f}}+1=\beta^{-1} \exp \left(-\theta x_{t+1}\right) z_{t+1}^{\mathrm{f}}$. Substituting in $z_{t+1}^{\mathrm{f}}=$ $\exp \left[a_{0}+a_{1}\left(x_{t}-\bar{x}\right)\right]$ from Proposition 1 and $E_{t} z_{t+1}^{\mathrm{f}}$ from equation (15) and then taking the unconditional expectation of $\log \left(R_{t+1}^{\mathrm{f}}\right)$ yields equation (18). We have

$$
\log \left(R_{t+1}^{\mathrm{f}}\right)-E\left[\log \left(R_{t+1}^{\mathrm{f}}\right)\right]=\alpha\left(x_{t+1}-\bar{x}\right)+a_{1} \varepsilon_{t+1}
$$

which in turns implies

$$
\operatorname{Var}\left[\log \left(R_{t+1}^{\mathrm{f}}\right)\right]=\alpha^{2} \operatorname{Var}\left(x_{t}\right)+\left(a_{1}\right)^{2} \sigma_{\varepsilon}^{2}+2 \alpha a_{1} \operatorname{Cov}\left(x_{t}, \varepsilon_{t}\right) .
$$

Substituting for $\operatorname{Var}\left(x_{t}\right)$ and $\operatorname{Cov}\left(x_{t}, \varepsilon_{t}\right)$ in the above expression yields equation (19).

\section{A.4 Proof of Proposition 2: Continuum of Intrinsic Rational Bubbles}

First consider the case where the agent can make use of the contemporaneous realization $z_{t}^{\mathrm{b}}$ when forming the rational expectation $E_{t} z_{t+1}^{\mathrm{b}}$. Iterating ahead the conjectured law of motion for $z_{t}^{\mathrm{b}}$ by one period and then taking the conditional expectation yields

$$
E_{t} z_{t+1}^{\mathrm{b}}=z_{t}^{\mathrm{b}} \exp \left[\lambda_{0}+\left(\rho \lambda_{1}+\lambda_{2}\right)\left(x_{t}-\bar{x}\right)+\frac{1}{2}\left(\lambda_{1}\right)^{2} \sigma_{\varepsilon}^{2}\right] .
$$

Substituting the above expression into the no-arbitrage condition (21) and then taking logarithms yields

$$
0=\log (\beta)+\theta x_{t}+\lambda_{0}+\left(\rho \lambda_{1}+\lambda_{2}\right)\left(x_{t}-\bar{x}\right)+\frac{1}{2}\left(\lambda_{1}\right)^{2} \sigma_{\varepsilon}^{2}
$$

where $\log \left(z_{t}^{\mathrm{b}}\right)$ has been cancelled from both sides. For equation (A.21) to hold, the constant terms and the coefficients on $x_{t}$ must separately sum to zero. Equilibrium therefore requires

$$
\begin{array}{r}
\frac{1}{2}\left(\lambda_{1}\right)^{2} \sigma_{\varepsilon}^{2}-\underbrace{\left(\rho \lambda_{1}+\lambda_{2}\right)}_{-\theta} \bar{x}+\log (\beta)+\lambda_{0}=0, \\
\theta+\rho \lambda_{1}+\lambda_{2}=0,
\end{array}
$$


which represent a system of two equations in three unknown constants $\lambda_{0}, \lambda_{1}$, and $\lambda_{2}$. The solutions to equations (A.22) and (A.23) define a continuum of intrinsic rational bubble equilibria.

Now consider the case where the agent can only make use of the lagged realization $z_{t-1}^{\mathrm{b}}$ when forming $E_{t} z_{t+1}^{\mathrm{b}}$. Iterating ahead the conjectured law of motion for $z_{t}^{\mathrm{b}}$ by one period and then substituting out $z_{t}^{\mathrm{b}}$ using the same law of motion yields

$$
z_{t+1}^{\mathrm{b}}=z_{t-1}^{\mathrm{b}} \exp \left\{2 \lambda_{0}+\left[\lambda_{1}(1+\rho)+\lambda_{2}\right]\left(x_{t}-\bar{x}\right)+\lambda_{2}\left(x_{t-1}-\bar{x}\right)+\lambda_{1} \varepsilon_{t+1}\right\},
$$

where I have eliminated $\left(x_{t+1}-\bar{x}\right)$ using the law of motion for consumption/dividend growth (33). Taking the conditional expectation of the above expression yields

$$
E_{t} z_{t+1}^{\mathrm{b}}=z_{t-1}^{\mathrm{b}} \exp \left\{2 \lambda_{0}+\left[\lambda_{1}(1+\rho)+\lambda_{2}\right]\left(x_{t}-\bar{x}\right)+\lambda_{2}\left(x_{t-1}-\bar{x}\right)+\frac{1}{2}\left(\lambda_{1}\right)^{2} \sigma_{\varepsilon}^{2}\right\} .
$$

Substituting the above expression into the no-arbitrage condition (21) and then taking logarithms yields

$$
\begin{aligned}
\log \left(z_{t}^{\mathrm{b}}\right)=\log \left(z_{t-1}^{\mathrm{b}}\right)+\log (\beta) & +\theta x_{t}+2 \lambda_{0}+\left[\lambda_{1}(1+\rho)+\lambda_{2}\right]\left(x_{t}-\bar{x}\right) \\
& +\lambda_{2}\left(x_{t-1}-\bar{x}\right)+\frac{1}{2}\left(\lambda_{1}\right)^{2} \sigma_{\varepsilon}^{2}
\end{aligned}
$$

which can be compared to the following expression for the logarithm of the conjectured law of motion:

$$
\log \left(z_{t}^{\mathrm{b}}\right)=\log \left(z_{t-1}^{\mathrm{b}}\right)+\lambda_{0}+\lambda_{1}\left(x_{t}-\bar{x}\right)+\lambda_{2}\left(x_{t-1}-\bar{x}\right) .
$$

Equation (A.26) will coincide exactly with equation (A.27) when the following equilibriums conditions are satisfied

$$
\begin{gathered}
\log (\beta)+2 \lambda_{0}-\left[\lambda_{1}(1+\rho)+2 \lambda_{2}\right] \bar{x}+\frac{1}{2}\left(\lambda_{1}\right)^{2} \sigma_{\varepsilon}^{2}=\lambda_{0}-\left(\lambda_{1}+\lambda_{2}\right) \bar{x} \\
\theta+\lambda_{1}(1+\rho)+\lambda_{2}=\lambda_{1}
\end{gathered}
$$

which are isomorphic to the equilibrium conditions (A.22) and (A.23).

\section{A.5 Asset Pricing Moments: Near-Rational Solution}

Starting from the approximate ALM (36), the law of motion of $\Delta \log \left(z_{t}\right)$ can be written as:

$$
\Delta \widehat{z}_{t}=(k-1)\left[\widehat{z}_{t-1}-E\left(\widehat{z}_{t}\right)\right]+m\left(x_{t}-\bar{x}\right),
$$

where $\widehat{z}_{t} \equiv \log \left(z_{t}\right)$. The above equation implies:

$$
\operatorname{Cov}\left(\Delta \widehat{z}_{t}, x_{t}\right)=(k-1) \operatorname{Cov}\left(\widehat{z}_{t-1}, x_{t}\right)+m \operatorname{Var}\left(x_{t}\right) .
$$

From (36), we have $\operatorname{Cov}\left(\widehat{z}_{t-1}, x_{t}\right)=[\rho m /(1-\rho k)] \operatorname{Var}\left(x_{t}\right)$, which can be substituted into (A.31) to yield equation (40) in the text. 
The nonlinear ALM for the price-dividend ratio, equation (33), can be rewritten as follows:

$$
\begin{aligned}
y_{t} & =\left(y_{t-1}+1\right) \beta \exp \left[b(1+\rho)\left(x_{t}-\bar{x}\right)+\theta x_{t-1}+\frac{1}{2} b^{2} \sigma_{\varepsilon}^{2}\right], \\
& =\left(y_{t-1}+1\right) k \exp \left[\left(\frac{m-\theta}{k}\right)\left(x_{t}-\bar{x}\right)+\theta\left(x_{t-1}-\bar{x}\right)\right],
\end{aligned}
$$

where I have eliminated $b$ and $b^{2}$ using the expressions for the Taylor series coefficients $k$ and $m$, as given by equations (37) and (38). Taking logarithms of the above expression yields

$$
\begin{aligned}
\widehat{y}_{t} & =\log \left[\exp \left(\widehat{y}_{t-1}\right)+1\right]+\log (k)+\left(\frac{m-\theta}{k}\right)\left(x_{t}-\bar{x}\right)+\theta\left(x_{t-1}-\bar{x}\right), \\
& \simeq n_{0}+n_{1}\left[\widehat{y}_{t-1}-E\left(\widehat{y}_{t}\right)\right]+\left(\frac{m-\theta}{k}\right)\left(x_{t}-\bar{x}\right)+\theta\left(x_{t-1}-\bar{x}\right),
\end{aligned}
$$

where $\widehat{y}_{t} \equiv \log \left(y_{t}\right)$, and $n_{0}$ and $n_{1}$ are Taylor series coefficients. Straightforward computations yield $n_{0}=\log [k /(1-k)]$ and $n_{1}=k$. The unconditional expectation of the above expression yields $E\left(\widehat{y}_{t}\right)=n_{0}$, as given by equation (41).

Using equation (A.33), the unconditional variance can be computed as follows:

$$
\begin{aligned}
\operatorname{Var}\left(\widehat{y}_{t}\right)= & E\left\{\left[\widehat{y}_{t}-E\left(\widehat{y}_{t}\right)\right]^{2}\right\} \\
= & \left(\frac{1}{1-k^{2}}\right)\left[\left(\frac{m-\theta}{k}\right)^{2}+\theta^{2}+2\left(\frac{m-\theta}{k}\right) \theta \rho\right] \operatorname{Var}\left(x_{t}\right), \\
& +\left[\frac{2(m-\theta) \rho+2 \theta k}{1-k^{2}}\right] \operatorname{Cov}\left(\widehat{y}_{t}, x_{t}\right),
\end{aligned}
$$

where $\operatorname{Cov}\left(\widehat{y}_{t}, x_{t}\right)$ can also be computed from equation (A.33).

The equity return is given by

$$
\begin{aligned}
R_{t+1} & =\left(\frac{z_{t+1}}{\beta \widehat{E}_{t} z_{t+1}}\right) \exp \left(\alpha x_{t+1}\right) \\
& =\frac{z_{t}^{k} \bar{z}^{1-k} \exp \left[m\left(x_{t+1}-\bar{x}\right)+\alpha x_{t+1}\right]}{\beta z_{t-1} \exp \left[b(1+\rho)\left(x_{t}-\bar{x}\right)+\frac{1}{2} b^{2} \sigma_{\varepsilon}^{2}\right]},
\end{aligned}
$$

where I have substituted in the approximate ALM (36) and the subjective expectation (30). Taking the unconditional expectation of $\widehat{R}_{t+1} \equiv \log \left(R_{t+1}\right)$ yields equation (42). From (A.35), we have

$$
\begin{aligned}
\widehat{R}_{t+1}-E\left(\widehat{R}_{t+1}\right)= & \underbrace{k\left[\widehat{z}_{t}-E\left(\widehat{z}_{t}\right)\right]}_{k^{2}\left[\widehat{z}_{t-1}-E\left(\widehat{z}_{t}\right)\right]+k m\left(x_{t}-\bar{x}\right)}-\left[\widehat{z}_{t-1}-E\left(\widehat{z}_{t}\right)\right] \\
& +(m+\alpha)\left(x_{t+1}-\bar{x}\right)-b(1+\rho)\left(x_{t}-\bar{x}\right),
\end{aligned}
$$


which can be used to compute an analytical expression for $\operatorname{Var}\left(\widehat{R}_{t+1}\right)$.

From equation (43), the law of motion for the percentage forecast error is given by

$$
\begin{aligned}
e r r_{t+1}-E\left(e r r_{t+1}\right)= & -\left(1-k^{2}\right)\left[\widehat{z}_{t-1}-E\left(\widehat{z}_{t}\right)\right] \\
& +[k m+m \rho-b(1+\rho)]\left(x_{t}-\bar{x}\right)+m \varepsilon_{t+1},
\end{aligned}
$$

where I have eliminated $\left[\widehat{z}_{t}-E\left(\widehat{z}_{t}\right)\right]$ using the approximate ALM (36). Equation (A.37) is used to compute $\operatorname{Corr}\left(\operatorname{err}_{t+1}, \operatorname{err}_{t}\right)=\operatorname{Cov}\left(\operatorname{err}_{t+1}, \operatorname{err}_{t}\right) / \operatorname{Var}\left(\operatorname{err}_{t+1}\right)$ and $R M S P E=$ $\left[E\left(e r r_{t+1}^{2}\right)\right]^{0.5}$ which are plotted in Figure 3 . 
Adam, K., A. Marcet, and Nicolini, J.P. (2008). 'Stock market volatility and learning', European Central Bank, working paper 862 (February).

Abel, A.B. (2002). 'An exploration of the effects of pessimism and doubt on asset returns', Journal of Economic Dynamics and Control, vol. 26 (July), pp. 1075-1092.

Amromin, G. and Sharpe, S.A. (2009). 'Expectations of risk and return among household investors: Are their Sharpe ratios countercycilical?,' Working paper (February).

Abreu, D. and Brunnermeier, M.K. (2003). 'Bubbles and crashes', Econometrica, vol. 71 (January), pp. 173-204.

Barberis, N., A. Shleifer, and Vishny, R.W. (1998). 'A model of investor sentiment', Journal of Financial Economics, vol. 49 (September), pp. 307-343.

Barsky, R.B. and De Long, J.B. (1993). 'Why does the stock market fluctuate?', Quarterly Journal of Economics, vol. 107 (May), pp. 291-311.

Bidarkota, P.V. and Dupoyet, B.V., (2007). 'Intrinsic bubbles and fat tails: A note', Macroeconomic Dynamics, vol. 11 (June), pp. 405-422.

Bohl, M.T. and Siklos, P.L. (2004). 'The present value model of U.S. stock prices redux: A new testing strategy and some evidence', Quarterly Review of Economics and Finance, vol. 44 (May), pp. 208-223.

Blanchard, O.J. (1979). 'Speculative bubbles, crashes, and rational expectations', Economics Letters, vol. 3 (November), pp. 387-389.

Blanchard, O.J. and Watson, M.W. (1982). 'Bubbles, rational expectations and financial markets', in (P. Wachtel, ed.), Crises in the Economic and Financial Structure, pp. 295-315. Lexington MA: Lexington Books.

Branch, W.A. and Evans, G.W. (forthcoming). 'Asset return dynamics and learning', Review of Financial Studies.

Brock, W.A. and Hommes, C.H. (1998). 'Heterogenous beliefs and routes to chaos in a simple asset pricing model', Journal of Economic Dynamics and Control, vol. 22 (August), pp. 12351274 .

Bullard, J., Evans, G., and Honkapohja, S. (forthcoming). 'A model of near-rational exuberance', Macroeconomic Dynamics.

Branch, W.A. and Evans, G.W. (forthcoming). 'Asset return dynamics and learning', Review of Financial Studies.

Burnside, C. (1998). 'Solving asset pricing models with Gaussian shocks', Journal of Economic Dynamics and Control, vol. 22 (March), pp. 329-340.

Calin, O.L., Chen, Y., Cosimano, T.F., and Himonas, A.A. (2005). 'Solving asset pricing models when the price-dividend ratio function is analytic', Econometrica, vol. 73 (May), pp. 961-982.

Cecchetti, S.G., Lam, P.-S. and Mark, N.C. (2000). 'Asset pricing with distorted beliefs: Are equity returns too good to be true?', American Economic Review, vol. 90 (September), pp. 787-805.

Coakley, J. and Fuertes, A. (2006). 'Valuation ratios and price deviations from fundamentals', Journal of Banking and Finance, vol. 30 (August), pp. 2325-2346.

Cochrane, J.H. (2009). 'How did Paul Krugman get is so wrong?', University of Chicago Booth School of Business, unpublished essay (September 16).

Collard, F. and Juillard, M. (2001). 'Accuracy of stochastic perturbation methods: The case of asset pricing models', Journal of Economic Dynamics and Control, vol. 25 (June), pp. 979-999.

Delong, J.B., Shleifer, A., Summers, L.H. and Waldmann, R.J. (1990). 'Noise trader risk in financial markets', Journal of Political Economy, vol. 98 (August), pp. 703-738. 
Diba, B.T. and Grossman, H.I. (1988). 'The theory of rational bubbles in stock prices', Economic Journal, vol. 98 (September), pp. 746-754.

Driffill, J. and Sola, M. (1998). 'Intrinsic bubbles and regime-switching', Journal of Monetary Economics, vol. 42 (July), pp. 357-373.

Engsted, T. (2006). 'Explosive bubbles in the cointegrated VAR model', Finance Research Letters, vol. 3 (June), pp. 154-162.

Evans, G.W. (1991). 'Pitfalls in testing for explosive bubbles in asset prices', American Economic Review, vol. 81 (September), pp. 922-930.

Evans, G.W. and Honkapohja, S. (2001). Learning and Expectations in Economics, Princeton: Princeton University Press.

Froot, K. and Obstfeld, M. (1991). 'Intrinsic bubbles: The case of stock prices', American Economic Review, vol. 81 (December), pp. 1189-1214.

Fukata, Y. (1998). 'A simple discrete approximation of continuous-time bubbles', Journal of Economic Dynamics and Control, vol. 22 (June), pp. 937-954.

Gerding, E.F. (2006). 'The next epidemic: bubbles and the growth and decay of securities regulation', Connecticut Law Review, vol. 38(3) (February), pp. 393-453.

Gürkaynak, R.S. (2008). 'Econometric tests of asset price bubbles: Taking stock', Journal of Economic Surveys, vol. 22 (February), pp. 166-186.

Hall, R.E. (2001). 'Struggling to understand the stock market', American Economic Review Papers and Proceedings, vol. 91 (May), pp. 1-11.

Hunter, W.C., Kaufman, G.G. and Pomerleano, M. (eds.), (2003). Asset Price Bubbles, The Implications for Monetary, Regulatory, and International Policies, Cambridge, MA: MIT Press.

Ikeda, S. and Shibata, A. (1992). 'Fundamentals-dependent bubbles in stock prices', Journal of Monetary Economics, vol. 30 (October), pp. 143-168.

Kamihigashi, T. (1998). 'Uniqueness of asset prices in an exchange economy with unbounded utility', Economic Theory, vol. 12 (July), pp. 103-122.

Keynes, J.M. (1936). The General Theory of Employment, Interest, and Money, New York: Harcourt-Brace.

Koustas, Z. and Serletis, A. (2005). 'Rational bubbles or peristent deviations from market fundamentals?', Journal of Banking and Finance, vol. 29 (October), pp. 2523-2539.

Lansing, K.J. (2006). 'Lock-in of extrapolative expectations in an asset pricing model,' Macroeconomic Dynamics, vol. 10 (June), pp. 317-348

Lansing, K.J. (2009). 'Speculative growth, overreaction, and the welfare cost of technologydriven bubbles', Federal Reserve Bank of San Francisco, working paper 2008-08 (September).

Lefévre, E. (1923). Reminiscences of a Stock Operator, New York: John Wiley (originally published by G.H. Doran).

LeRoy, S.F. (2004). 'Rational exuberance,' Journal of Economic Literature, vol. 152 (September), pp. 783-804.

LeRoy, S.F. and Porter, R.D. (1981). 'The present-value relation: Tests based on implied variance bounds', Econometrica, vol. 49 (May), pp. 555-577.

Lucas, R.E. (1978). 'Asset prices in an exchange economy', Econometrica, vol. 46 (November), pp. 1429-1445.

Montrucchio, L. and Privileggi. F. (2001). 'On fragility of bubbles in equilibrium asset pricing models of Lucas-type', Journal of Economic Theory, vol. 101 (November), pp. 158-188. 
Nerlove, M. (1983). 'Expectations, plans, and realizations in theory and practice', Econometrica, vol. 51 (September), pp. 1251-1279.

Santos, M.S. and Woodford. M. (1997). 'Rational asset pricing bubbles', Econometrica, vol. 65 (January), pp. 19-57

Scheinkman, J.A. and Xiong, W. (2003). 'Overconfidence and speculative bubbles', Journal of Political Economy, vol. 111 (December), pp. 1183-1219.

Shiller, R.J. (1981). 'Do stock prices move too much to be justified by subsequent changes in dividends?', American Economic Review, vol. 71 (June), pp. 421-436.

Shiller, R.J. (2003). 'From efficient markets theory to behavioral finance', Journal of Economic Perspectives, vol. 17 (Winter), pp. 83-104.

Timmerman, A. (1996). 'Excess volatility and predictability of stock prices in autoregressive dividend models with learning', Review of Economic Studies, vol. 63 (October), pp. 523-557.

Tirole, J. (1982). 'On the possibility of speculation under rational expectations', Econometrica, vol. 50 (September), pp. 1163-1181.

Tirole, J. (1985). 'Asset bubbles and overlapping generations', Econometrica, vol. 53 (November), pp. 1499-1528.

Van Norden, S. and Schaller, H. (1999). 'Speculative behavior, regime switching, and stock market crashes', in (P. Rothman, ed.), Nonlinear Time Series Analysis of Economic and Financial Data, pp. 321-356. Boston: Kluwer.

Vissing-Jorgensen, A. (2004). 'Perspectives on behavioral finance: Does "irrationality" disappear with wealth? Evidence from expectations and actions', in (M. Gertler and K. Rogoff, eds.), NBER Macroeconomics Annual 2003, pp. 139-194. Cambridge, MA: MIT Press.

Weil, P. (1990). 'On the possibility of price decreasing bubbles', Econometrica , vol. 58 (November), pp. 1467-1474.

Wu, Y. (1997). 'Rational bubbles in the stock market: Accounting for the U.S. stock-price volatility', Economic Inquiry, vol. 358 (April), pp. 309-319. 
(a) Fundamental Price-Dividend Ratio

$\alpha=1.5, \rho=-0.1$

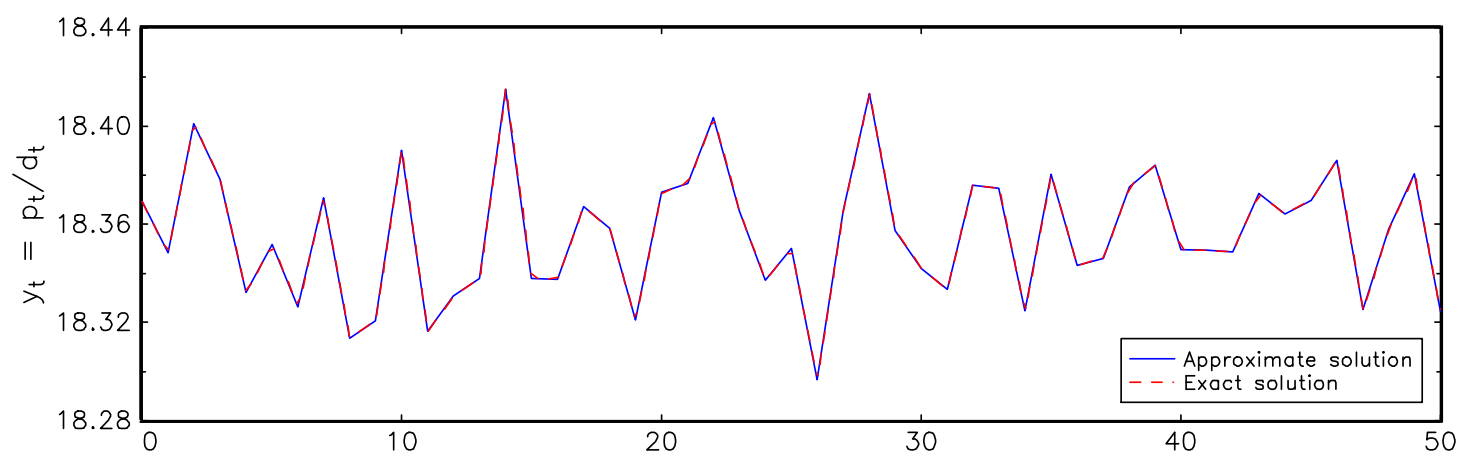

(b) Fundamental Price-Dividend Ratio

$\alpha=10, \rho=0.50$

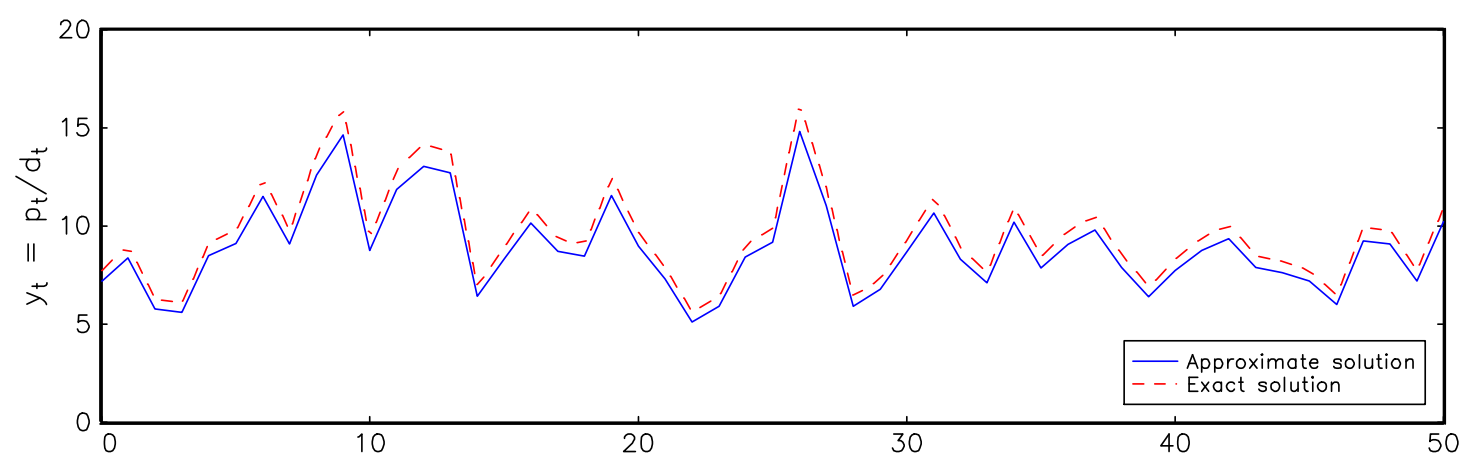

Figure 1: Approximate and exact solutions for fundamental price-dividend ratio. 


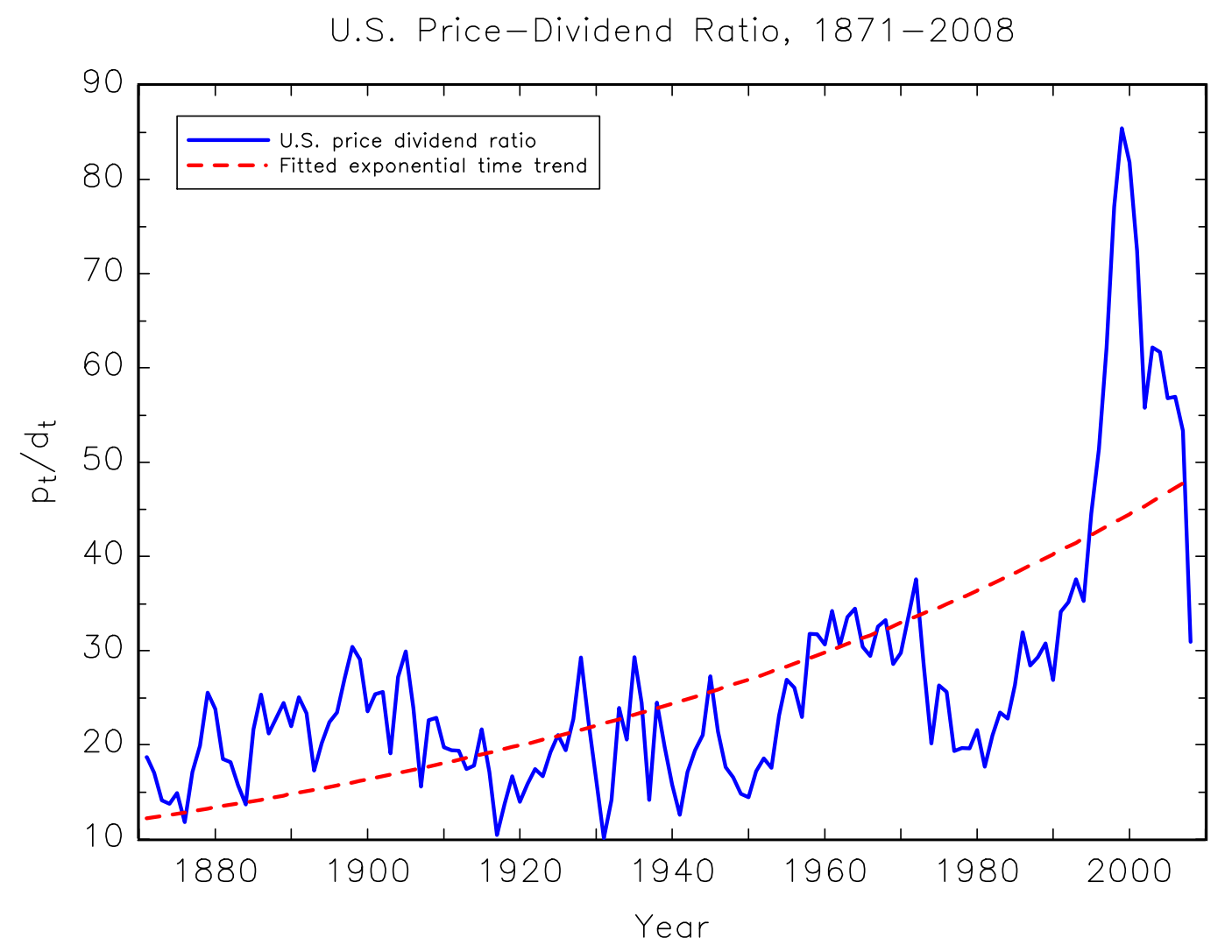

Figure 2: The annual drift rate in the U.S. price-dividend ratio is about 0.01 . 
(a) Solving for the Near-Rational Equilibrium

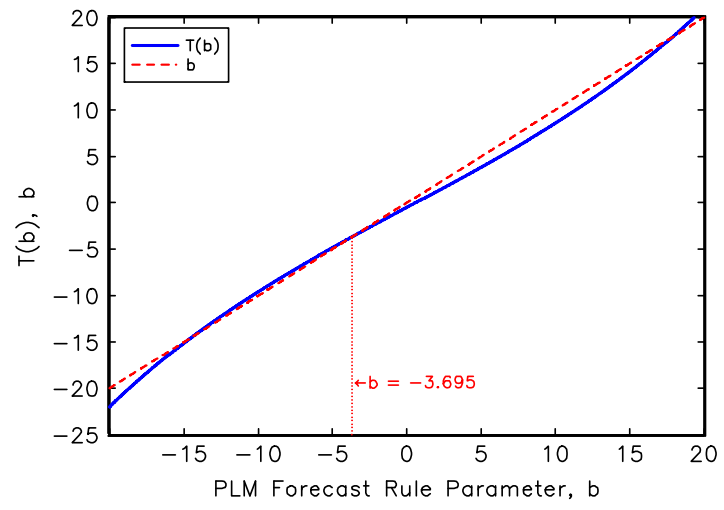

(c) Autocorrelation of Percentage Forecast Errors

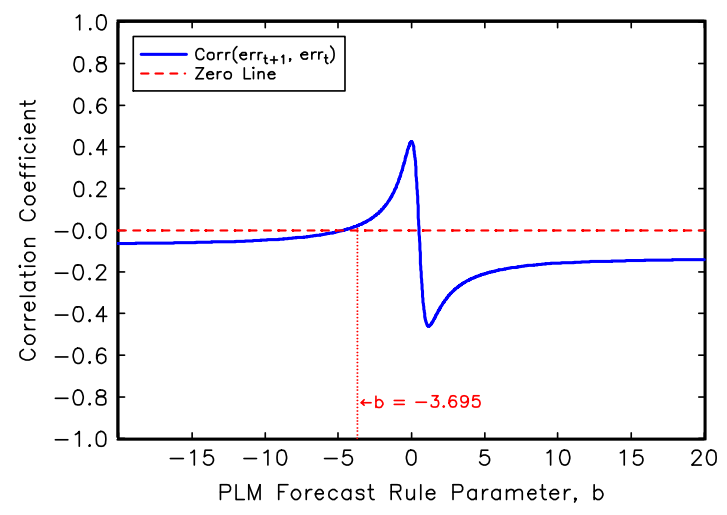

(b) Stability of the Near-Rational Equilibrium

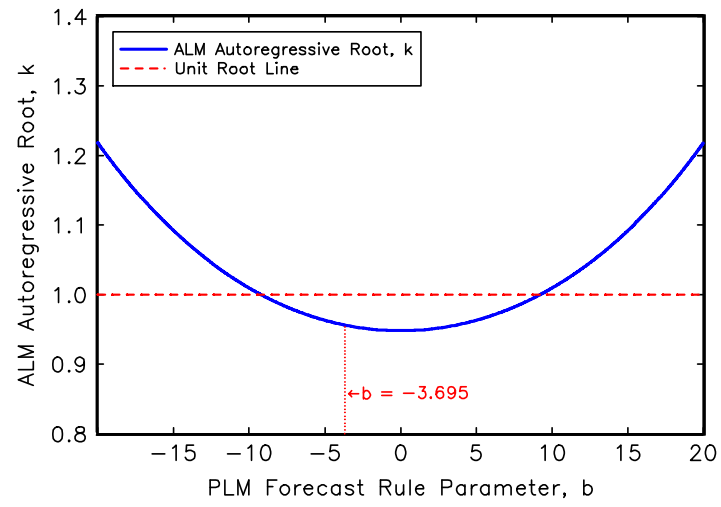

(d) Root Mean Squared Percentage Forecast Error

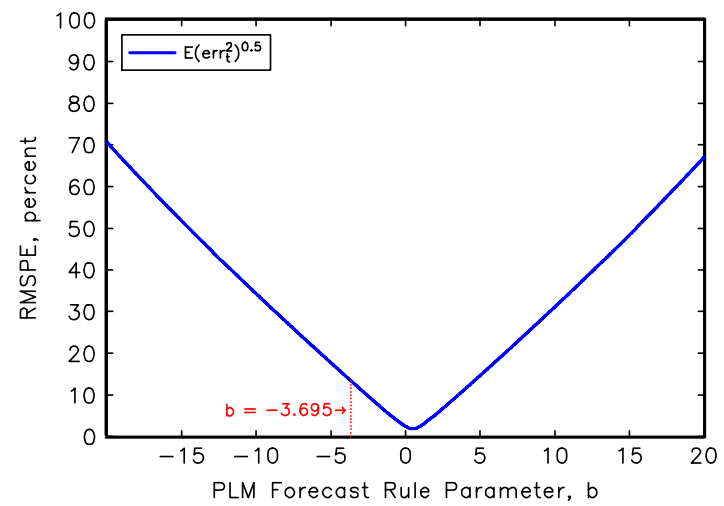

Figure 3: Properties of the near-rational equilibrium. 


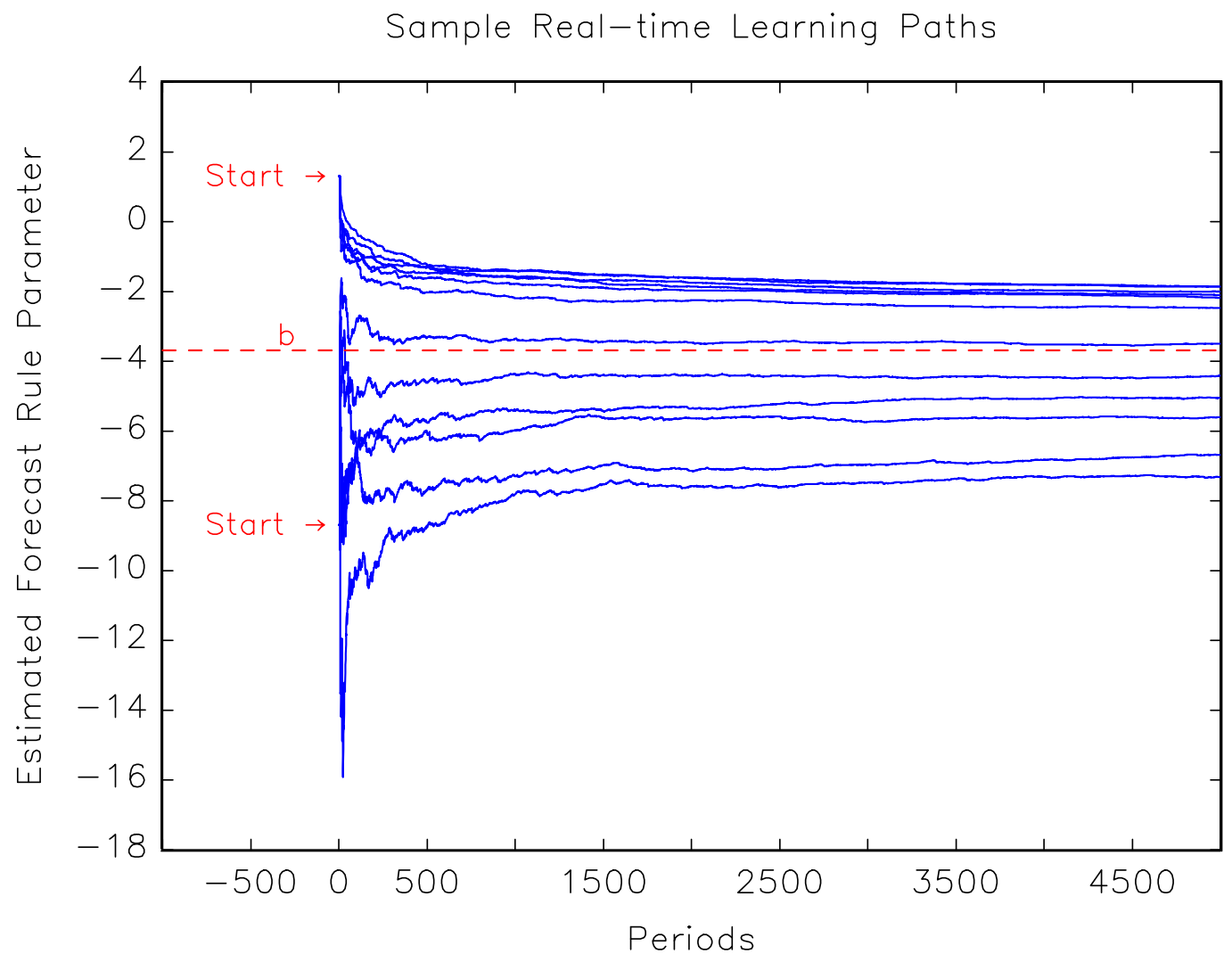

Figure 4: Sampling variation in $\operatorname{Cov}\left[\Delta \log \left(z_{t}\right), x_{t}\right]$ affects the real-time learning paths. 
(a) Froot-Obstfeld Rational Bubble $\left(\lambda_{1}>0\right)$

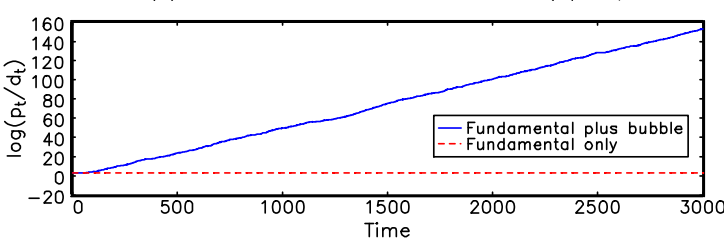

(c) Driftless Rational Bubble $\left(\lambda_{1}>0\right)$

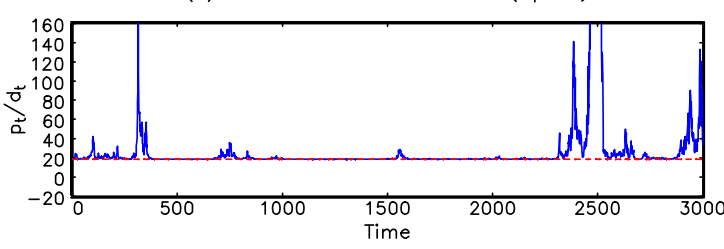

(e) Driftless Rational Bubble $\left(\lambda_{1}<0\right)$

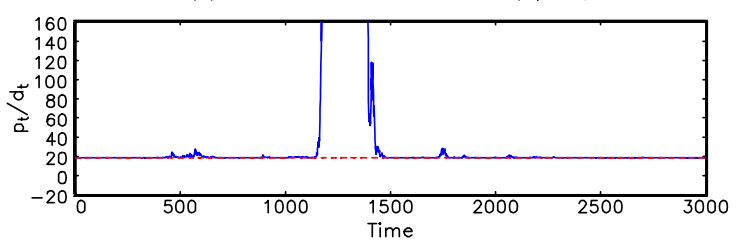

(g) Near-Rational Solution

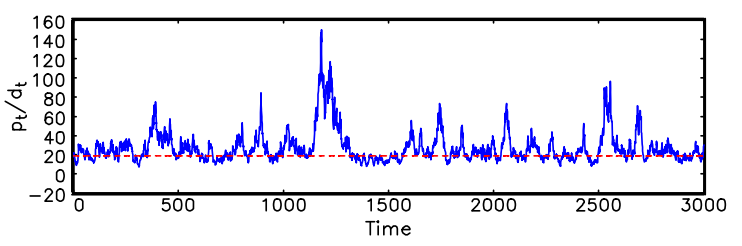

(b) Froot-Obstfeld Rational Bubble $\left(\lambda_{1}>0\right)$

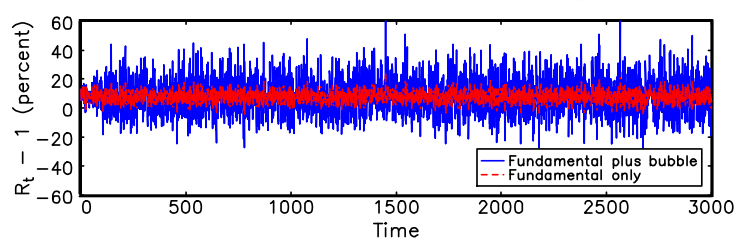

(d) Driftless Rational Bubble $\left(\lambda_{1}>0\right)$

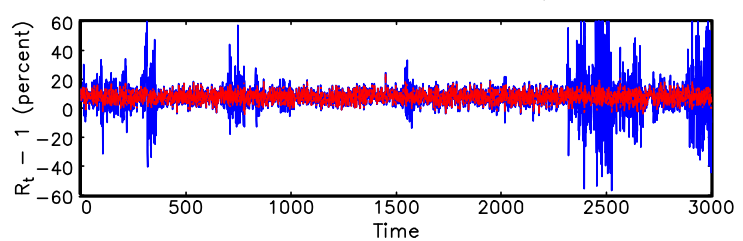

(f) Driftless Rational Bubble $\left(\lambda_{1}<0\right)$

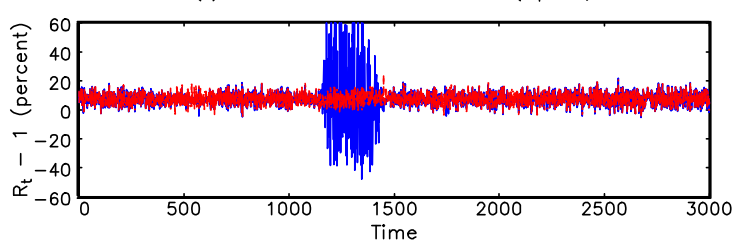

(h) Near-Rational Solution

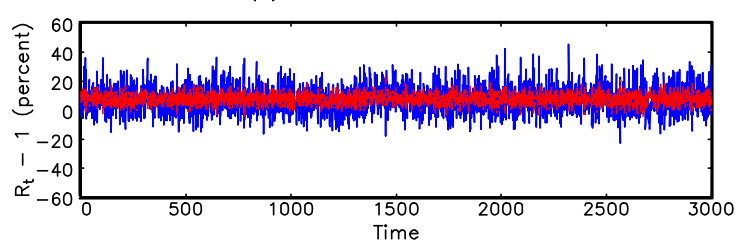

Figure 5: Left panels: price-dividend ratio. Right panels: net equity return. 